\title{
Relevant mediators involved in and therapies targeting the inflammatory response induced by activation of the NLRP3 inflammasome in ischemic stroke
}

Qingxue $\mathrm{Xu}^{1,2 \dagger}$, Bo Zhao ${ }^{2 \dagger}$, Yingze Ye $\mathrm{e}^{1,3}$, Yina $\mathrm{Li}^{1,2}$, Yonggang Zhang ${ }^{1,3}$, Xiaoxing Xiong ${ }^{1,3^{*}}$ and Lijuan $\mathrm{Gu}^{1,2^{*}}$

\begin{abstract}
The nucleotide-binding oligomerization domain (NOD)-like receptor (NLR) family pyrin domain-containing 3 (NLRP3) inflammasome is a member of the NLR family of inherent immune cell sensors. The NLRP3 inflammasome can detect tissue damage and pathogen invasion through innate immune cell sensor components commonly known as pattern recognition receptors (PRRs). PRRs promote activation of nuclear factor kappa B (NF-kB) pathways and the mitogen-activated protein kinase (MAPK) pathway, thus increasing the transcription of genes encoding proteins related to the NLRP3 inflammasome. The NLRP3 inflammasome is a complex with multiple components, including an NAIP, CIITA, HET-E, and TP1 (NACHT) domain; apoptosis-associated speck-like protein containing a CARD (ASC); and a leucine-rich repeat (LRR) domain. After ischemic stroke, the NLRP3 inflammasome can produce numerous proinflammatory cytokines, mediating nerve cell dysfunction and brain edema and ultimately leading to nerve cell death once activated. Ischemic stroke is a disease with high rates of mortality and disability worldwide and is being observed in increasingly younger populations. To date, there are no clearly effective therapeutic strategies for the clinical treatment of ischemic stroke. Understanding the NLRP3 inflammasome may provide novel ideas and approaches because targeting of upstream and downstream molecules in the NLRP3 pathway shows promise for ischemic stroke therapy. In this manuscript, we summarize the existing evidence regarding the composition and activation of the NLRP3 inflammasome, the molecules involved in inflammatory pathways, and corresponding drugs or molecules that exert effects after cerebral ischemia. This evidence may provide possible targets or new strategies for ischemic stroke therapy.
\end{abstract}

Keywords: NLRP3 inflammasome, Ischemic stroke, Inflammation, Reactive oxygen species, Signaling pathway

\section{Introduction}

Stroke is a disease with high mortality and disability rates worldwide. Its prevalence rate increases annually, and the affected population is becoming increasingly younger. Stroke imparts heavy economic burdens on the

\footnotetext{
*Correspondence: xiaoxingxiong@whu.edu.cn; gulijuan@whu.edu.cn

${ }^{\dagger}$ Qingxue Xu and Bo Zhao contributed equally to this work.

${ }^{1}$ Central Laboratory, Renmin Hospital of Wuhan University, Wuhan 430060, China

Full list of author information is available at the end of the article
}

families of patients and on society as a whole $[1,2]$. According to its different etiologies and pathogeneses, stroke is clinically divided into hemorrhagic stroke, which is caused by cerebral vascular rupture, and ischemic stroke, which is triggered by arterial embolization or thromboembolism in the cerebrum. Ischemic stroke accounts for more than $80 \%$ of stroke cases, while hemorrhagic stroke accounts for fewer than $20 \%$ of cases. In this review, we focus on ischemic stroke because it is the condition with the second-highest

(c) The Author(s). 2021 Open Access This article is licensed under a Creative Commons Attribution 4.0 International License, which permits use, sharing, adaptation, distribution and reproduction in any medium or format, as long as you give appropriate credit to the original author(s) and the source, provide a link to the Creative Commons licence, and indicate if changes were made. The images or other third party material in this article are included in the article's Creative Commons licence, unless indicated otherwise in a credit line to the material. If material is not included in the article's Creative Commons licence and your intended use is not permitted by statutory regulation or exceeds the permitted use, you will need to obtain permission directly from the copyright holder. To view a copy of this licence, visit http://creativecommons.org/licenses/by/4.0/ The Creative Commons Public Domain Dedication waiver (http://creativecommons.org/publicdomain/zero/1.0/) applies to the data made available in this article, unless otherwise stated in a credit line to the data. 
mortality rate in the world after heart disease [3]. Focal ischemic stroke is the most common type of ischemic stroke [4-6]. There are many genetic and environmental risk factors for stroke. A study on single-gene diseases has suggested that common variants in approximately 35 sites are strongly related to the risk of stroke [7]. Additionally, various health-related and environmental factors, such as high blood pressure, diabetes, high cholesterol, high body mass index (BMI), smoking, and a history of stroke, all increase the risk of stroke [8]. The poststroke pathophysiological process is complicated and includes intracellular ion homeostasis disruption, acidosis, increased cytoplasmic $\mathrm{Ca}^{2+}$ concentrations, toxicity mediated by reactive oxygen species (ROS), bioenergy failure, arachidonic acid production, cytokinemediated cytotoxicity, neuron and glial cells activation, complement activation, blood-brain barrier (BBB) destruction and leukocyte extravasation [9]. Above all, these factors can affect the functions and molecules of neurons, glial cells, and vascular cells [10]. Ischemic brain tissue injury is associated with the degree and duration of decreased blood flow. Greater severity and longer durations of obstruction are associated with more severe brain tissue injuries, including brain tissue edema, nerve cell dysfunction, and irreversible cerebral infarction, which lead to cognitive dysfunction and movement disorders [11]. Cerebral edema can also result in herniation and death [3]. When ischemic brain tissue is reperfused with blood, the cellular metabolic rate and oxygen consumption increase, leading to mitochondrial damage, increased ROS generation, increased cytoplasmic $\mathrm{Ca}^{2+}$ concentrations, and neutrophil infiltration and in turn aggravating cell damage via the inflammatory response [12]. This process is called cerebral ischemia/reperfusion (I/R) injury (IRI), which can be treated by targeting and attenuating inflammation through a series of therapeutic methods [13]. In addition, the ischemic penumbra has received much research attention. The penumbra is an area that can be saved to limit the negative effects of ischemic stroke [14], but there is a risk of the penumbra transforming into an ischemic zone, so interventions involving reperfusion of the penumbra after acute ischemic stroke warrant further consideration [15]. To date, there are no effective drugs for stroke treatment that do not elicit severe side effects. Intravenous tissue plasminogen activator (tPA) treatment and intravascular thrombectomy have been shown to be efficient for the treatment of acute ischemic stroke. However, tPA treatment is restricted to a narrow window, which limits its clinical application [16, 17]. In addition, treatment of stroke with tPA increases the risk of cerebral hemorrhage and induces neuronal excitotoxicity [18]. Studies in vitro and in vivo have demonstrated that the single-chain form of tPA (sc-tPA) selectively strengthens transduction of the $\mathrm{N}$-methyl-D-aspartate receptor (NMDAR) signal and enhances NMDAR-mediated $\mathrm{Ca}^{2+}$ influx and neurotoxicity in cultured cortical neurons [19]. Neuroprotectors reduce infarct volume and inhibit neuronal death in cultures and stroke animal models but have failed in clinical trials because of their harmful effects and inefficiency [20, 21]. Molecular danger signals called damage-associated molecular patterns (DAMPs), such as high-mobility group box 1 (HMGB1), are released after multiple types of cell damage. In addition, pathogen-associated molecular patterns (PAMPs) derived from bacteria can activate the innate immune system through pattern recognition receptors (PRRs), which has recently been highlighted as an important inflammatory mechanism. The PRRs of neurons and astrocytes then activate the mitogen-activated protein kinase (MAPK) and nuclear factor kappa B (NF-kB) pathways [22, 23]. The NLRP3 inflammasome is a key intermediate, and treatments targeting upstream and downstream signaling pathways of NLRP3 may be novel strategies for stroke therapy [24]. In this review, we describe the composition and activation of the NLRP3 inflammasome in ischemic stroke and the molecules involved in associated inflammatory pathways. In addition, possible targets and new strategies related to the NLRP3 inflammasome for the therapy of ischemic stroke are described.

\section{The NLRP3 inflammasome}

NLRP3, a classic nucleotide-binding oligomerization domain (NOD)-like receptor (NLR), is the most widely studied inflammatory complex and is believed to be closely associated with aseptic inflammation [25]. The NLRP3 inflammasome includes three protein subunits, the adaptor protein, apoptosis-associated speck-like protein containing a CARD (ASC), the receptor NLRP3, and the effector pro-caspase-1 [26], and participates in various infectious, inflammatory, and immune diseases [27]. The NLRP3 receptor comprises three domains, including a central NAIP, CIITA, HET-E, and TP1 (NACHT) domain; an N-terminal pyrin domain (PYD); and a C-terminal leucine-rich repeat (LRR) domain [28]. NLRs are members of the PRR family. NLRs are intracellular microbial receptors, and some NLRs can perceive danger signals, such as the presence of bacterial RNA and flagella, through both PAMP recognition and DAMP recognition [29]. Particles such as silicon dioxide, aluminum hydroxide, and amyloid fibers cause lysosomal membrane rupture, which helps microbial molecules enter the cytoplasm, thereby activating the NLRP3 inflammasome $[30,31]$. The NACHT domain participates in the formation of the NLRP3 receptor and forms the central core of the inflammasome with the 
participation of adenosine triphosphate (ATP) after activation of oligomerization. The PYD is necessary for the binding of the NLR protein to the adaptor protein ASC [32, 33]. The inflammasome acts as a molecular platform to activate caspase- 1 and then modulate the innate immune response [34]. Caspase-1 serves as an effector agent to cleave proteins and process prointerleukin (IL)-1 $\beta$ and pro-IL-18 into the mature forms IL-1 $\beta$ and IL-18, respectively, and these mature cytokines are secreted into the extracellular space to perform their functions. ASC, which is visible as specks in apoptotic cells [35], mediates pro-caspase-1 self-hydrolysis and subsequent pro-IL-1 $\beta$ maturation but is not significantly involved in caspase-1-mediated neuronal death [33]. One study has indicated that caspase-12 can suppress the NLRP3 inflammasome by disturbing caspase-1 activation, which is associated with susceptibility to sepsis [36]. MCC950, an NLRP3 inhibitor, can reduce the expression of NLRP3 in ischemic brain tissue, and we have discovered that an NLRP3 inhibitor can reduce neuronal apoptosis, cerebral infarct size, and neurological dysfunction [37].

\section{Molecular and other mechanisms involved in activation of the NLRP3 inflammasome}

Activation of NLRP3 is thought to involve a variety of advanced signals, most of which are mutually synergistic but not exclusive. Studies have shown that NLRP3 receptors can sense disturbances in homeostasis and respond through several processes, as follows: (1) a low $\mathrm{K}^{+}$concentration in the cytoplasm can trigger NLRP3 activation, (2) intracellular $\mathrm{Ca}^{2+}$ accumulation can induce harmful signaling pathways and activate the NLRP3 inflammasome, (3) lysosomal instability can stimulate cathepsin release and induce NLRP3 activation, and (4) mitochondrial injury-induced ROS production can activate NLRP3 and damage mitochondrial DNA (Fig. 1).

\section{$\mathrm{K}^{+}$-mediated activation of NLRP3}

A decreased intracellular $\mathrm{K}^{+}$concentration is a significant factor in NLRP3 inflammasome activation [38]. Studies have shown that reducing $\mathrm{K}^{+}$levels in the cytoplasm induces NLRP3 inflammasome activation in vitro $[39,40]$. Reductions in intracellular $\mathrm{K}^{+}$levels can activate the NLRP3 inflammasome by influencing pore-forming

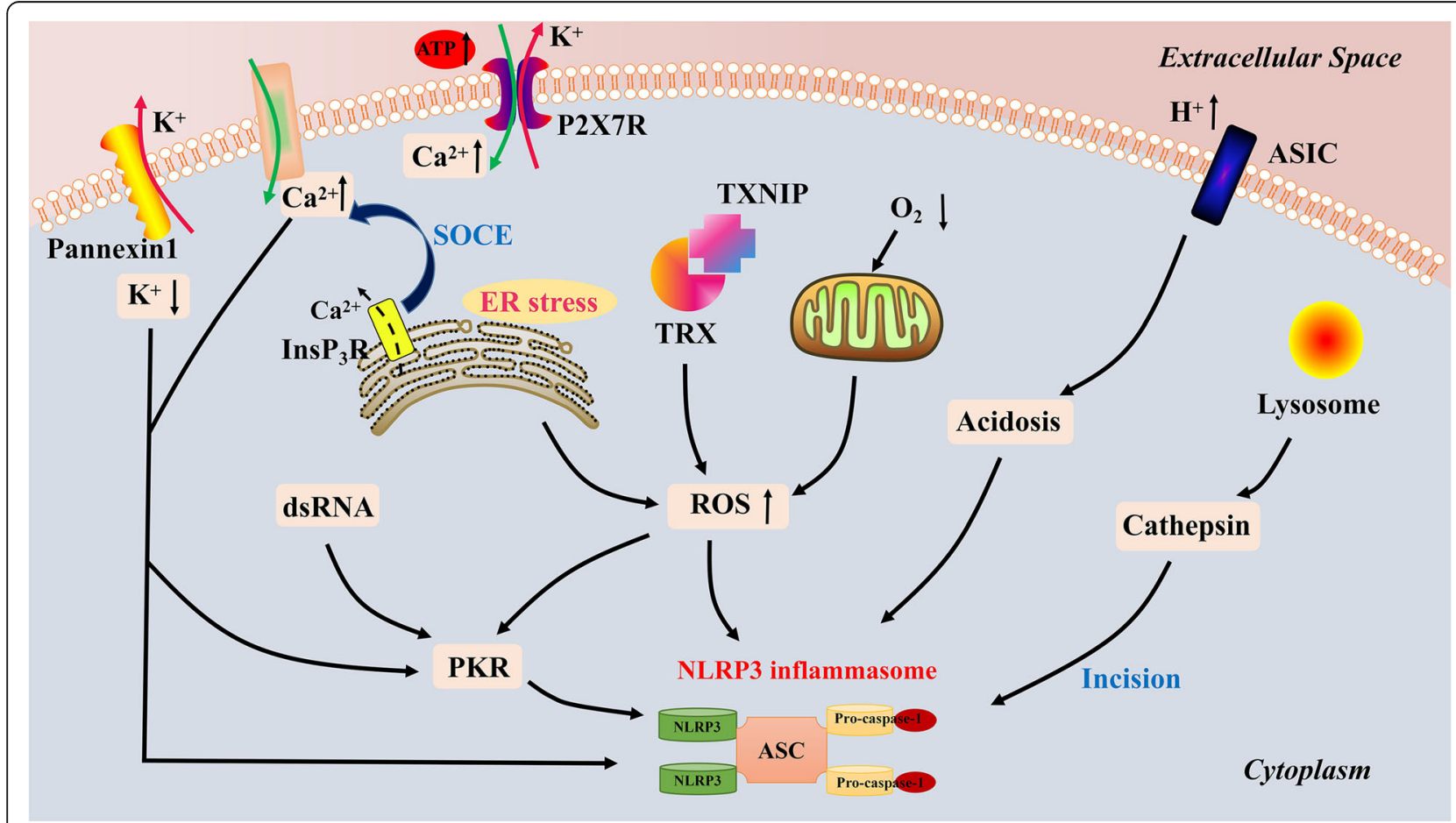

Fig. 1 Mechanisms of NLRP3 inflammasome activation. Decreases in intracellular $\mathrm{K}^{+}$concentrations, increases in intracellular $\mathrm{Ca}^{2+}$ concentrations, and excessive ROS production activate the NLRP3 inflammasome. As an inhibitor of the TRX system, TXNIP has been proven to mediate generation of large amounts of ROS and to activate the NLRP3 inflammasome. The activation of P2X7R caused by elevated ATP concentrations leads to increased intracellular $\mathrm{Ca}^{2+}$ concentrations and $\mathrm{K}^{+}$outflow, resulting in activation of the NLRP3 inflammasome. Cathepsin is released into the cytoplasm after lysosomal membrane rupture, which induces activation of the NLRP3 inflammasome via cleavage of NLRP3 receptorassociated inhibitory domains or inhibitory proteins. dsRNA, increased intracellular $\mathrm{Ca}^{2+}$ levels, $\mathrm{K}^{+}$outflow, increased ROS and other cellular stress factors activate PKR, and PKR activates the NLRP3 inflammasome. Anaerobic glycolysis results in the accumulation of large amounts of $\mathrm{H}^{+}$and lactic acid, causing acidosis and ultimately activating the NLRP3 inflammasome 
or endogenous ion channels [41]. Notably, the $\mathrm{K}^{+}$channel inhibitor glyburide efficiently inhibits inflammasome activation [42, 43]. Passive ATP release may be connected to P2X4 receptors in the plasma membranes of adjacent neurons and glial cells, closing receptors and resulting in $\mathrm{K}^{+}$efflux [44, 45]. Damaged cells also passively release $\mathrm{K}^{+}$. Together, these mechanisms lead to increases in extracellular $\mathrm{K}^{+}$concentrations and activation of membrane pannexin 1 channels [46]. Closure of pannexin 1 channels contributes to further ATP release and purinergic ligand-gated ion channel 7 receptor (P2X7R) activation, which restimulate the pannexin 1 channels to form a positive feedback loop, thus causing excessive $\mathrm{K}^{+}$ outflow and reducing inflow [44, 45, 47].

\section{$\mathrm{Ca}^{2+}$-mediated activation of NLRP3}

Some studies have indicated that an increasing intracellular $\mathrm{Ca}^{2+}$ concentration activates the NLRP3 receptor both in vitro and in vivo [48]. During focal brain ischemia, high intracellular $\mathrm{Ca}^{2+}$ levels may be caused mainly by increased intracellular $\mathrm{Ca}^{2+}$ influx and decreased $\mathrm{Ca}^{2+}$ efflux due to increased intracellular $\mathrm{Ca}^{2+}$ release in damaged neurons and glial cells $[49,50] . \mathrm{Ca}^{2+}$ release by injured cells can lead to intracellular $\mathrm{Ca}^{2+}$ overload through a specific mechanism. Briefly, necrotic cells in the ischemic core passively release $\mathrm{Ca}^{2+}$, increasing the extracellular $\mathrm{Ca}^{2+}$ concentration. The $\mathrm{Ca}^{2+}$ binds to and activates $\mathrm{Ca}^{2+}$ sensing receptors (CaSRs) and GPR6CA molecules on adjacent neuronal cells and glial cells, indirectly mediating NLRP3 receptor activation and simultaneously reducing intracellular cyclic adenosine monophosphate (cAMP) concentrations [51, 52]. Reductions in cytoplasmic cAMP concentrations can promote activation of the NLRP3 receptor [53-55]. After activation of cAMP and NLRP3, membrane-bound phospholipase C (PLC), which cleaves phosphatidylinositol-4,5-diphosphate (PIP2) into inositol triphosphate (InsP3) and diacylglycerol (DAG), can be activated [56, 57]. InsP3 interacts with the InsP3 receptor (InsP3-R) located in the endoplasmic reticulum (ER) to stimulate $\mathrm{Ca}^{2+}$ release $[48,52,56,57]$. Experiments have shown that both ER $\mathrm{Ca}^{2+}$ release and extracellular $\mathrm{Ca}^{2+}$ influx are necessary for activation of the NLRP3 inflammasome. Pretreatment or incubation in $\mathrm{Ca}^{2+}$-free medium with brief exposure to thapsigargin (Tg), a suppressant of the sarcoplasmic/ER $\mathrm{Ca}^{2+}$-ATPase (SERCA) pump, attenuates activation of the NLRP3 inflammasome. ER-released $\mathrm{Ca}^{2+}$ can trigger extracellular $\mathrm{Ca}^{2+}$ influx through storeoperated $\mathrm{Ca}^{2+}$ entry (SOCE) [58]. In addition, the increased concentration of $\mathrm{Ca}^{2+}$ leads to $\mathrm{Ca}^{2+}$ accumulation in the mitochondrial matrix through the mitochondrial $\mathrm{Ca}^{2+}$ uniporter (MCU) and the loss of mitochondrial transmembrane potential, thus activating the NLRP3 inflammasome. Other studies have shown that after the membrane attack complex (MAC) is formed, some $\mathrm{Ca}^{2+}$ is released through the ER via ryanodine receptors [59]. In conclusion, $\mathrm{Ca}^{2+}$ can indirectly activate the NLRP3 inflammasome through functional changes in the ER and mitochondria. The low-affinity $\mathrm{Na}^{+} / \mathrm{Ca}^{2+}$ exchanger (NCX) and high-affinity $\mathrm{Ca}^{2+}$-ATPase in the plasma membrane are the major transporters responsible for regulating intracellular $\mathrm{Ca}^{2+}$ levels and returning plasma $\mathrm{Ca}^{2+}$ concentrations to resting levels to maintain homeostasis [60]. Under conditions of excessive intracellular $\mathrm{Na}^{+}, \mathrm{NCX}$ activates its reverse exchange mode, mediating $\mathrm{Ca}^{2+}$ influx and $\mathrm{Na}^{+}$efflux, which results in intracellular $\mathrm{Ca}^{2+}$ overload [61]. Selective inhibitors of the NCX reverse mode have been developed and tested in animal models of stroke and have been conclusively shown to reduce brain damage [62, 63].

\section{ROS-mediated activation of NLRP3}

ROS play important roles in inflammation, oxidative stress, changes in blood vessel tension, and oxidation of low-density lipoprotein cholesterol (LDL-C) [64, 65]. ROS are also necessary for NLRP3 inflammasome activation. When the brain undergoes ischemic and hypoxic damage, large amounts of ROS are generated due to mitochondrial damage or insufficient oxygen supply, and these ROS in turn further disrupt mitochondrial function and structure [66]. There is evidence that mitochondria may be important sources of ROS related to NLRP3 inflammasome activation [67]. As byproducts of oxidative phosphorylation, ROS can be produced by mitochondria; these ROS not only continuously activate the NLRP3 inflammasome but also continue to damage mitochondria. When the ER is under stress, nicotinamide adenine dinucleotide phosphate (NADPH) oxidase (NOX) in the ER can induce ROS generation to restore ER homeostasis [68]. Excessive ROS production in the ER leads to mitochondrial $\mathrm{Ca}^{2+}$ deposition and further aggravates mitochondrial damage [69]. Mitochondrial autophagy is a crucial adjuster of NLRP3 activation because it eliminates dysfunctional and damaged mitochondria, thus ultimately reducing ROS levels. Increases in the numbers of damaged and dysfunctional mitochondria after treatment with mitochondrial autophagy inhibitors can enhance activation of the NLRP3 inflammasome [70]. Oxidized mitochondrial DNA can also lead to excitation of the NLRP3 receptor, consistent with the role of mitochondria in the signal transduction of the NLRP3 inflammasome [71]. During cerebral ischemia, ROS levels can increase through disturbance of the electron transport chain or activation of NOX, xanthine dehydrogenase, phospholipase A2 (PLA2), or nitric oxide synthase (NOS) [72-74]. A variety of experiments involving interference with mitochondrial function and uncoupling of the electron transport chain have proven that mitochondrial dysfunction can enhance ROS 
production and ultimately activate the NLRP3 receptor; this situation may occur after cerebral ischemia. When mitochondrial autophagy is disrupted, ROS production increases significantly, and the NLRP3 receptor is activated [75]. Some studies have shown that nuclear factor erythrocyte 2-related factor 2 (NRF2) is also necessary for NLRP3 activation [76, 77]. However, other studies have shown that NRF2 regulates antioxidant gene levels to support cell survival during oxidative stress while also inhibiting NLRP3 activity by limiting ROS levels [78].

\section{TXNIP-mediated activation of NLRP3}

Thioredoxin (TRX)-interacting protein (TXNIP) is an endogenous suppressor of the TRX system that mainly inhibits cellular mercaptan production and has antioxidant and anti-inflammatory effects. However, increasing evidence has shown that TXNIP exerts its proinflammatory effect by activating the NLRP3 inflammasome [79]. In addition, numerous studies have shown that TXNIP may act as a primary mediator linking various undesirable stimuli, such as oxidative stress [80] and inflammation [81], to the NLRP3 inflammasome. TXNIP is a significant molecular site and signaling molecule in ER stress (ERS) and the inflammatory response [82]. In the context of ERS, TXNIP produces large amounts of ROS, which activate the NLRP3 inflammasome, resulting in IL-1 $\beta$ secretion $[82,83]$. After ischemic stroke, TXNIP exacerbates cerebral injury through redox imbalance and subsequently activates the NLRP3 inflammasome [84]. In unaffected cells, TXNIP binds to and inhibits redoxrelated TRX, and the presence of the complex is associated with elevations in cytoplasmic ROS levels, which cause TXNIP to bind to NLRP3 receptor domains (mainly the LRR domain) and thus induce activation of NLRP3 receptors [5, 67, 85]. Recent evidence also suggests that NRF2, which is regarded as a pivotal molecule in the antioxidant stress system, inhibits TXNIP and NLRP3 inflammasome activation in IRI of the cerebrum [86]. This suggests that TXNIP-mediated activation of the NLRP3 inflammasome is a key factor in ischemic stroke. Therefore, the associated signaling pathway could be a new target for the treatment of ischemic stroke.

\section{P2X7R-mediated activation of NLRP3}

P2X7R is a nonselective ATP-gated cation channel located on the membranes of various immune cells. Activation of P2X7R produces a range of harmful effects, including intracellular $\mathrm{Ca}^{2+}$ concentration increases, glutamate release, and NLRP3 inflammasome activation $[37,87]$. These adverse effects may lead to aggravation of ischemic brain tissue injury and excitotoxicity and even to irreversible damage. Brilliant Blue G (BBG), an antagonist of P2X7R, can significantly reduce neuronal apoptosis, cerebral infarct size, and nerve function defects and save brain tissue. After ischemic stroke, ATP accumulates in damaged and inflamed tissue, and the increase in ATP concentration activates P2X7R, leading to intracellular $\mathrm{K}^{+}$efflux that activates the NLRP3 inflammasome [88]. Therefore, the NLRP3 inflammasome has been reported to be a potential downstream signaling factor of P2X7R [89]. Thus, blocking P2X7R activation is a novel strategy for neuroprotection in the context of ischemic stroke.

\section{Cathepsin-mediated activation of NLRP3}

The lysosomal cysteine protease cathepsin, a sterile particle, is released into the cytoplasm following lysosomal membrane destruction and rupture caused by stimulation with DAMP particulate crystals [90-92]. The released cathepsin induces NLRP3 inflammasome activation by cleaving the inhibitory domain or repressive protein associated with the NLRP3 receptor [93-95]. Sterile particles (including crystals and other factors originating from cholesterol clefts released by cerebral atherosclerotic vessels) as well as uric acid and $\mathrm{Ca}^{2+}$ released from crystals formed by necrotic tissues in the ischemic area can be absorbed into the lysosomes of various types of cells (including recruited astrocytes, microglia and infiltrating white blood cells) via engulfment, phagocytosis or scavenger receptor-mediated membrane absorption, which subsequently causes lysosomal instability [96-99]. In addition, some exogenous particulates, such as silica, alum, and asbestos, do not dissolve but are instead repeatedly phagocytosed and transported into lysosomes, which can cause lysosomal rupture and continuous cathepsin release [31]. The cathepsin lysosomal cysteine protease family is a family of 11 enzymes that were initially thought to function only in lysosomes; however, recent studies have shown that cathepsins have additional lysosomal and extracellular functions [100-102]. Cathepsin-B plays a crucial role in NLRP3 inflammasome activation, and a cathepsin- $B$ inhibitor has been shown to specifically inhibit this process [103]. In addition, studies using combinations of multiple cathepsin inhibitors have indicated that multiple cathepsins can effectively activate the NLRP3 inflammasome [91, 104, 105]. Overall, the evidence indicates that cathepsins play key roles in NLRP3 activation, which provides new ideas for stroke treatment.

\section{PKR-mediated activation of NLRP3}

Protein kinase R (PKR) belongs to the serine/threonineprotein kinase family, which is commonly activated by double-stranded RNA (dsRNA) [106, 107]. During cerebral ischemia, PKR is activated by various cellular stress factors, such as increased intracellular $\mathrm{Ca}^{2+}$ levels, $\mathrm{K}^{+}$efflux, and elevated ROS levels; activated PKR then participates in the inflammatory response. PKR is an 
indispensable component for inflammasome assembly and activation [108]. A recent experiment demonstrated that complement $5 \mathrm{a}$ receptor 2 (C5aR2) promotes NLRP3 activation by increasing dsRNA-dependent PKR expression [109, 110]. We demonstrated that Epac1 regulates PKR phosphorylation, leading to inactivation, in retinal lysates generated from retinal endothelial cells (RECs) with Epac1-specific knockout. PKR inhibition experiments have demonstrated that PKR deficiency reduces the expression levels of NLRP3, caspase-1, and IL-1 $\beta$. In addition, some studies have indicated that PKR modulates the NLRP3 inflammasome in RECs. Epac1 regulates PKR phosphorylation, leading to PKR inactivation and significantly reducing NLRP3 signaling [111]. PKR has also been reported to mediate harmful palmitic acid (PA)-induced inflammation through the Jun $\mathrm{N}$ terminal kinase (JNK)/NF- $\mathrm{B}$ /NLRP3 signaling pathway in cultured cardiomyocytes [112]. P58 can inhibit PKR and is associated with activation of inflammasomes. A comparison of primary bone marrow-derived macrophages (BMDMs) between p58-knockout mice and wildtype mice showed that $\mathrm{p} 58$ deficiency increases PKR and NF- $\mathrm{kB}$ activation and increases proinflammatory gene expression [113]. However, studies have also shown that activation of PKR is not required in ASC oligomers or the NLRP3 inflammasome when macrophages exposed to nonactivated anthrax lethal toxin undergo pyroptosis [114]. Moreover, in PKR-deficient macrophages, pro-IL18 is still transformed into IL-18, indicating that PKR is not necessary in this context [115]. The above findings demonstrate that the roles of PKR in NLRP3 inflammasome activation and the inflammatory response still need to be clarified in future studies.

\section{Acidosis-mediated activation of NLRP3}

After stroke, anaerobic glycolysis occurs due to vascular obstruction, cerebral tissue ischemia, and hypoxia. This process provides compensatory and transient energy support but produces large amounts of lactic acid and $\mathrm{H}^{+}$, leading to local $\mathrm{pH}$ decreases that cause irreversible cerebral cell death [116]. Lactic acidosis is thus strongly associated with ischemic stroke [117]. Acidosis is also regarded as an inducer of NLRP3 inflammasome activity. The NLRP3 receptor is activated by intracellular acidosis and reductions in intracellular $\mathrm{K}^{+}$concentrations, although the mechanism remains to be clarified [118]. An acidic extracellular environment can trigger cell signaling events through changes in the surface or intracellular environment. On the cell surface, acid-sensitive ion channels (ASICs) directly activated by protons are triggered by acidosis to induce cell reactions [119]. ASICs are widely expressed in the central nervous system (CNS), including in the cerebral cortex, hippocampus, and cerebellum [120]. Ischemic cerebral acidosis leads to neuronal damage, and the damaging effect is mediated partly by ASICs [121, 122]. In cerebral ischemia, the passive release of $\mathrm{H}^{+}$from necrotic cells results in extracellular acidosis in the ischemic area $[118,123]$. Components of the acidic extracellular environment can bind to neurons and glial cells via $\mathrm{H}^{+}$-activated ASICs [124]. In the CNS, ASIC1 is the most widely distributed member of the ASIC family; in particular, the ASICla isomer is $\mathrm{Ca}^{2+}$ permeable and is associated with neuronal injury mediated by acidosis under ischemic conditions [121, 122, 125]. The use of ASIC blockers significantly reduces brain infarct volume, prevents damage, and has protective effects on the ischemic brain [121]. In addition, ASIC1 does not depend on the conduction of $\mathrm{Ca}^{2+}$, and ASIC1a-induced phosphorylation of receptor-interacting protein 1 (RIP1) has been found to be a new type of injury that occurs through the interaction of ASICla with the serine/threonine kinase RIP1 and subsequent induction of pyroptosis to mediate acidosis and ischemic cell death [126].

\section{Role of the NLRP3 inflammasome in ischemic stroke}

NLRP3 inflammasome-related neuronal death in ischemic stroke

Pyroptosis is a kind of programmed cell death that differs from necrosis and apoptosis and is induced entirely by cleaved caspase- 1 to cause inflammatory cell death [127]. Caspase-1 dependence is characteristic of pyroptosis. Necrotic morphological changes, including membrane rupture, pore formation, and edema, promote the release of materials within inflammatory cells and damage to the actin cytoskeleton. In contrast, pyroptosis results in complete mitochondrial destruction and ballooning (small bubble formation) without the release of cytochrome-c (Cyt) [128-131]. At the molecular level, pyroptosis is characterized by gasdermin D (GSDMD)mediated cell death [132]. Activated caspase-1 cleaves GSDMD and triggers intracellular GSDMD-N domain oligomerization, which results in the formation of pores to release IL-1 $\beta$, IL-18, and HMGB1. In addition, active caspase- 1 mediates pro-IL-1 $\beta /$ IL-18 maturation into IL$1 \beta / \mathrm{IL}-18$, leading to inflammation $[129,133]$. Caspase- 1 thus cleaves and activates GSDMD, IL- $1 \beta$, and IL-18, which then escape into the extracellular space through pores generated by GSDMD [132] (Fig. 2). Hence, GSDMD may be a potential therapeutic target to inhibit caspase-1-mediated pyroptosis [134]. After stroke, extracellular and intracellular environments undergo metabolic changes, including reductions in ATP, efflux of intracellular $\mathrm{K}^{+}$, increases in intracellular $\mathrm{Ca}^{2+}$, high mitochondrial production of ROS that cannot be eliminated via normal methods, and leukocyte recruitment to damaged sites. In the contexts of these stresses, the 


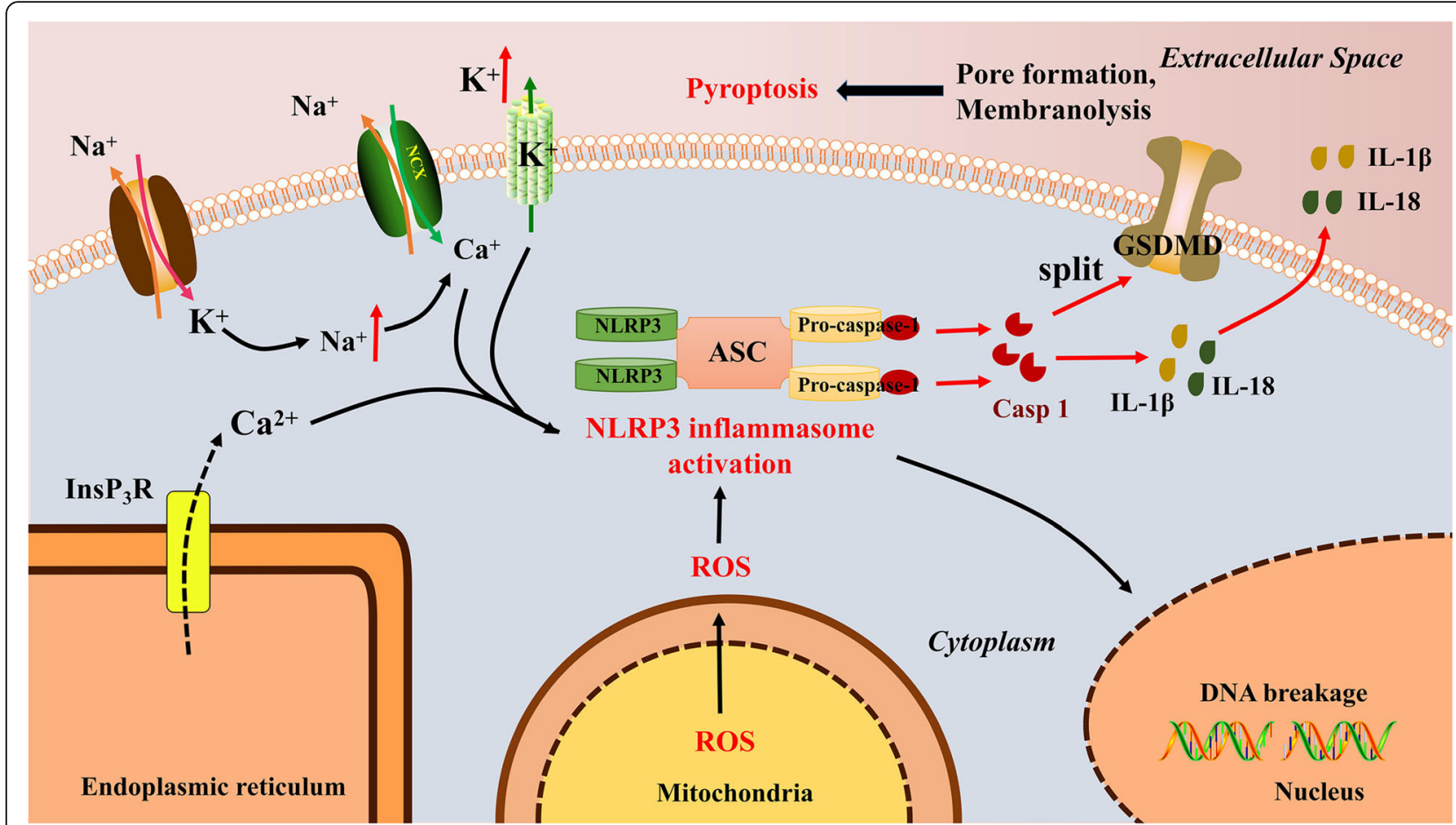

Fig. 2 Metabolic changes in the intracellular and extracellular environments activate the NLRP3 inflammasome, leading to pyroptosis. Pyroptosis is characterized by GSDMD-mediated cell death. Extracellular and intracellular environments undergo metabolic changes, including reductions in ATP, efflux of intracellular $\mathrm{K}^{+}$, increases in intracellular $\mathrm{Ca}^{2+}$, and production of large amounts of ROS by mitochondria; the ROS cannot be normally removed, and the NLRP3 inflammasome is activated, prompting pro-caspase-1 to self-cleave into caspase-1. Then, caspase-1 lyses and activates GSDMD, leading to pore formation, membrane lysis, and DNA breakage.

NLRP3 inflammasome is activated, prompting procaspase-1 self-cleavage for maturation. Caspase- 1 then cleaves pro-IL-1 $\beta$ and pro-IL-18 into IL-1 $\beta$ and IL-18, respectively. In addition, during stroke, necrotic cells secrete danger signals called DAMPs that activate PRRs, resulting in expression of inflammasome components, which causes caspase- 1 activation and IL-1 $\beta$ cytokine production through a process mediated by NOD1 or NOD2 and Toll-like receptors (TLRs) [127, 135]. Notably, hypothermia inhibits pyroptosis and thus can alleviate pyroptosis after cerebral ischemia. A151, an inhibitor of cyclic GMP-AMP (cGAMP) synthase (cGAS), markedly reduces the expression of calcitonin gene-related peptides (CGRPs) and decreases the activity of absent in melanoma 2 (AIM2) and the expression of pyroptosis-associated proteins, including GSDMD, caspase-1, IL-1 $\beta$, and IL-18 [136]. Because pyroptosis is an important neuronal death process, the specific pyrophosphate inhibitor Vx765, which targets the typical inflammasome, has potential therapeutic value for ischemic stroke [137]. These findings show that targeted pyroptosis can improve neurological function in animal models of ischemic stroke. Taken together, these reports suggest that targeting cellular pyroptosis pathways is a novel approach for treating ischemic stroke.

\section{Role of NLRP3 in COVID-19- or cytokine storm- associated stroke}

In November 2019, a severe respiratory illness with a high mortality rate, coronavirus disease 2019 (COVID19), began to spread worldwide. The pathogen responsible for the disease is severe acute respiratory syndrome coronavirus 2 (SARS-CoV-2). In humans, death from COVID-19 can result from an excessive systemic inflammatory response, or "cytokine storm," which is a sign of severe disease [138]. In addition, patients with COVID19 often present with neurological clinical manifestations, including headache, loss of smell, and even stroke. COVID-19 has been suggested to increase the incidence of stroke; the incidence of stroke in critical patients is as high as 6\% [139]. In addition, studies have shown that COVID-19-associated ischemic stroke is more severe and has a higher mortality rate than non-COVID-19-associated ischemic stroke [140]. SARS-CoV-2 can affect the nervous system in a number of ways. For example, it can penetrate the CNS through olfactory nerve endings (dysosmia is considered a precursor of COVID-19) [141]. Some authors have suggested that SARS-CoV-2 may enter the lung-gut-brain axis of the vagus nerve or enter the CNS via the hematogenous pathway during viremia in severely affected patients [142, 143]. On the 
one hand, a large number of inflammatory cytokines are released to destroy the $\mathrm{BBB}$ and promote the entry of the virus. Astrocytes can be directly attacked by SARSCoV-2 [144, 145]. On the other hand, astrocytes and microglia are highly sensitive to systemic proinflammatory cytokines and receive proinflammatory signals from endothelial cells to induce the expression of proinflammatory genes, thereby promoting neuroinflammation and neurodegeneration $[142,146]$. The angiotensinconverting enzyme type 2 (ACE-2) receptor has been proven to exist in nerve tissue and vascular endothelial cells; SARS-CoV-2 can bind to brain cells through this receptor and then attack the cells, resulting in nervous system disorders [147]. In human ACE-2-transgenic mice, SARS-CoV-2 can infect neurons and cause neuronal death in an ACE-2-dependent manner [148]. Some studies have also failed to detect SARS-CoV-2 in any cerebrospinal fluid samples, indicating that the nervous system is involved through immune mechanisms rather than through direct viral infection [149]. The levels of various circulating cytokines have been found to be upregulated in the context of COVID-19 through observational studies [150, 151]. In severe cases of SARS-CoV-2 infection, cytokine release syndrome, namely, a cytokine storm, can be observed [139, 152]; the storm is accompanied by increases in circulating C-reactive protein (CRP) levels and erythrocyte sedimentation rates (ESRs) [153]. It is believed that activation of macrophages caused by SARS-CoV-2 infection results in the production and consequent accumulation of inflammatory cytokines, including IFN- $\alpha$, IFN- $\gamma$, IL-6, IL-1 $\beta$, IL-17, TNF$\alpha$, transforming growth factors (TGF- $\beta$ ) and chemokines (CXCL10, CXCL8, CXCL9, CCL2, CCL3, and CCL5). It has also been reported that IL-6 and the NLRP3 inflammasome are the main immune components that mediate the immune response and inflammatory cytokine storm during pathogen infection [154]. We believe that the NLRP3 inflammasome might be one of the triggering factors of the cytokine storm during COVID-19. Viruses, as PAMPs, invade the body and activate dysregulated and excessive immune reactions through a variety of receptors (including NLRs, TLRs and cGAS), which causes overactivation of the NLRP3 inflammasome and then strongly induces the secretion and release of excessive amounts of proinflammatory cytokines and chemokines, resulting in a cytokine storm [155]. The whole SARSCoV-2 virus or its components can also activate the NLRP3 inflammasome by increasing extracellular ATP levels and activating P2X7R, which is widely expressed in CNS cells, such as microglia and oligodendrocytes. P2X7R activation is induced by increases in angiotensin II (Ang-II) resulting from loss of ACE-2 function due to binding with SARS-CoV-2; the increases in Ang-II lead to activation of the NLRP3 inflammasome, ultimately promoting neuroinvasion and neuroinflammation [156]. Both viruses and their protein components can cross the $\mathrm{BBB}$ and enter the CNS to initiate neuroinflammation [157]. Recently, it has been reported that a SARS-CoV-2 protein binds to mannan-binding lectin (MBL) and activates the complement cascade (ComC) and the coagulation cascade ( $\mathrm{CoaC})$ through the MBL-MBL-associated serine protease 2 (MASP-2) protease complex, thereby activating the NLRP3 inflammasome [158]. Activated NLRP3 releases DAMPs through GSDMD. For example, high levels of the nuclear protein HMGB1, a DAMP downstream of NLRP3, reflect excessive inflammation during viral infection [159].

COVID-19 is reported to be related to clotting disorders [160]. Coagulation and thrombosis may begin in the lung and other infected organs with endothelial damage, complement activation complicated by the procoagulant effects of IL-6 and neutrophilic granulocyte recruitment [161]. As a result, the levels of D-dimers (fibrinogen breakdown products that form in blood vessels) increase, and disseminated intravascular coagulation occurs [162, 163]. Patients with COVID-19 show hypercoagulability, so SARS-CoV-2 may cause thrombus formation at different sites in patients with thrombotic propensity [164], which may also increase the risk of stroke. In view of the above information, we speculate that targeting the immune cascade, the NLRP3 inflammasome, and hypercoagulability may be beneficial for reducing the incidence of stroke.

\section{Targeting various components of inflammasome pathways for ischemic stroke treatment}

At present, effective treatments for ischemic stroke are scarce. The current treatment for acute ischemic stroke involves intravenous tPA administration for blood flow restoration. However, this strategy is limited by the narrow therapeutic window and high risk of intracerebral hemorrhage associated with tPA treatment [16]. Oxidative stress and inflammation participate in cerebral IRI, and proper regulation of inflammation could contribute significantly to stroke protection and therapy [13]. Researchers have identified NLRP3 as a critical mediator of neuronal damage and inflammation after stroke, and experiments targeting the NLRP3 inflammasome pathway have shown promising results. These findings have revealed a new path for researchers in the search for effective and reliable treatments for ischemic cerebral apoplexy [165]. The new approaches can be divided into treatments targeting gene products and treatments targeting gene expression (Fig. 3) (Table 1). In addition, studies have demonstrated that distinctive drugs can target different neurocyte types and pathways to yield corresponding effects (Table 2). The feasibility of using 


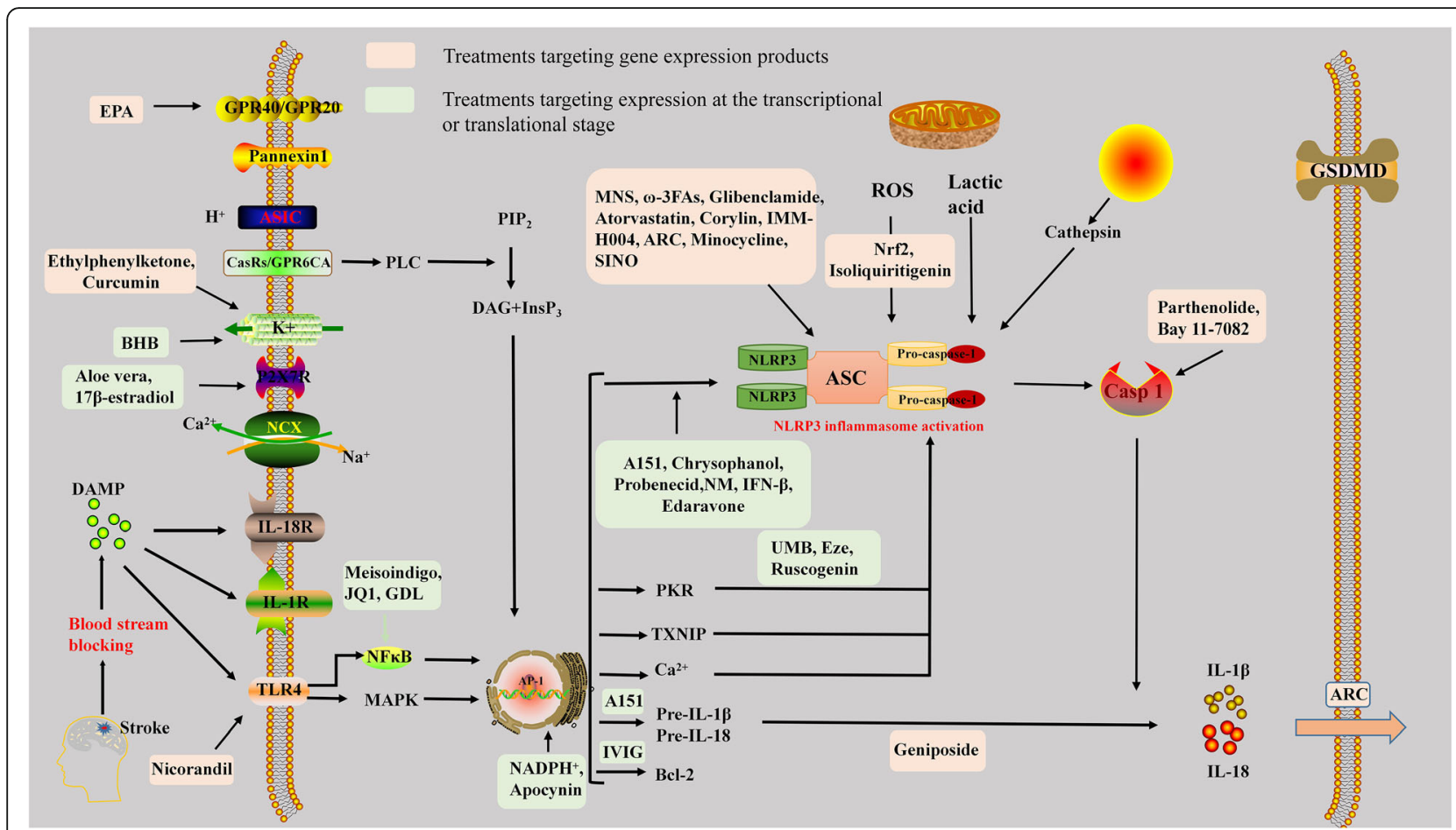

Fig. 3 Possible drug actions targeting the different mechanisms of NLRP3 inflammasome activation. EPA: eicosapentaenoic acid; MNS: 3,4methylenedioxy-beta-nitrostyrene; $\omega$-3FAs: omega-3 fatty acids; ARC: arctigenin; SINO: sinomenine; Nrf2: nuclear factor erythrocyte 2-related factor 2; BHB: $\beta$-hydroxybutyrate; NM: nafamostat mesilate; IFN- $\beta$ : interferon- $\beta$; UMB: umbelliferone; Eze: ezetimibe; IVIG: intravenous immunoglobulin; GDL: ginkgo diterpene lactones; DAMP: damage-associated molecular pattern; GPR40/GPR20: G protein-coupled receptor (GPCR) 40/20; ASIC: acid-sensing ion channel; CasR/GPR6CA: $\mathrm{Ca}^{2+}$-sensing receptor/GPCR family C group 6 member A; NCX: $\mathrm{Na}^{+} / \mathrm{Ca}^{2+}$ exchanger; IL-18R: interleukin18 receptor; IL-1R: interleukin-1 receptor; TLR4: Toll-like receptor 4; NF-KB: nuclear factor kappa B; MAPK: mitogen-activated protein kinase; PIP2: phosphatidylinositol-4,5-diphosphate; PLC: phospholipase C; DAG: diacylglycerol; InsP3: inositol triphosphate 3; ROS: reactive oxygen species; ASC: apoptosis-associated speck-like protein with a CARD; PKR: protein kinase R; TXNIP: thioredoxin-interacting protein; BCl-2: B-cell lymphoma 2; Casp 1: caspase-1; GSDMD: gasdermin D

small molecules and drugs for stroke therapy needs to be further investigated.

\section{Treatments targeting gene expression products to impact NLRP3 inflammasome activation}

MCC950, which is known for its action on the NLRP3 inflammasome, can inhibit not only the ASC oligomerization induced by typical or atypical NLRP3 activation but also the processing, secretion, and release of Il-1 $\beta$ and IL-18 [166]. During ischemic stroke, MCC950 can reduce neurological defects and cerebral edema, improve the integrity of the BBB, and decrease neuronal and glial cell death after stroke [199]. In addition, the NLRP3 receptor can be excited by $\mathrm{K}^{+}$efflux; thus, suppressing $\mathrm{K}^{+}$efflux or increasing the extracellular $\mathrm{K}^{+}$concentration can inhibit NLRP3 receptor activation. Research has shown that suppression of voltage-gated $\mathrm{K}^{+}$channels (using ethyl phenyl ketone)

Table 1 Inhibitors of the NLRP3 inflammasome in ischemic stroke

\begin{tabular}{ll}
\hline Categories & Drugs or molecules \\
\hline Acting on gene expression products & MCC950, parthenolide, Bay 11-7082, MNS, omega-3 fatty acids, atorvastatin, Nrf2, ethylphenyl ketone, \\
& glibenclamide, IMM-H004, eicosapentaenoic acid, geniposide, sinomenine, corylin, minocycline, arcti- \\
& genin, nicorandil, curcumin
\end{tabular}


Table 2 Cell categories of drugs acting on and related effect/pathways after ischemic stroke

\begin{tabular}{|c|c|c|c|c|}
\hline & Categories & Models & Effects/pathways & References \\
\hline MCC950 & Microglia & $\mathrm{ICH}$ models in mice & $\begin{array}{l}\text { Inhibiting ASC oligomerization and secretion and } \\
\text { release of } I I-1 \beta \text { and } I L-18\end{array}$ & {$[166]$} \\
\hline $\begin{array}{l}\text { Parthenolide, Bay } \\
11-7082\end{array}$ & Macrophages & Mice BMDM (named NG5) & Inhibiting the activity of caspase- 1 & [167] \\
\hline MNS & Macrophages & Mice BMDM & Inhibiting ASC speck formation and oligomerization & [168] \\
\hline $\begin{array}{l}\text { Omega-3 fatty } \\
\text { acids }\end{array}$ & Macrophages & Mice BMDM & $\begin{array}{l}\text { Inhibiting the production ofproinflammatory } \\
\text { cytokines }\end{array}$ & [169] \\
\hline $\begin{array}{l}\text { Isoliquiritigenin } \\
\text { (ILG) }\end{array}$ & Neurons & Rats model & $\begin{array}{l}\text { Inhibiting NLRP3 inflammasome activation mediated } \\
\text { by NF-KB }\end{array}$ & {$[78,170]$} \\
\hline IMM-H004 & Neurons & pMCAO rats model & Anti-inflammatory pathway dependent on CKLF1 & [171] \\
\hline $\begin{array}{l}\text { Eicosapentaenoic } \\
\text { acid }\end{array}$ & Neurons, Microglia & $\begin{array}{l}\text { MCAO mice, OGD model of BV2 } \\
\text { cell line }\end{array}$ & Obstructing GPR40 and GPR20 & [172] \\
\hline Geniposide & Microglia & BV2 cell line OGD/R model & $\begin{array}{l}\text { Reducing inflammatory cytokine levels; increasing } \\
\text { the autophagic activity }\end{array}$ & [173] \\
\hline Sinomenine & Astrocytes, Microglia & $\begin{array}{l}\text { MCAO mice model, Astrocyte, } \\
\text { Microglia OGD model }\end{array}$ & $\begin{array}{l}\text { Inhibiting the NLRP3 inflammasome mediated by } \\
\text { AMPK pathway }\end{array}$ & [174] \\
\hline Corylin & Microglia & $\begin{array}{l}\text { LPS-induced BV2 cell line } \\
\text { inflammation }\end{array}$ & Alleviating LPS-induced inflammation & [175] \\
\hline Minocycline & Microglia & $\begin{array}{l}\text { tMCAO mice model; OGD/R model } \\
\text { of BV2 cell line }\end{array}$ & $\begin{array}{l}\text { Stoping microglial activation; inhibiting maturation } \\
\text { and release of proinflammatory cytokines }\end{array}$ & [176] \\
\hline Arctigenin & Neurons & MCAO rats, OGD/R neuron model & $\begin{array}{l}\text { Inhibiting sirtuin-1 and decreasing activation of the } \\
\text { NLRP3 inflammasome }\end{array}$ & {$[177]$} \\
\hline Nicorandil & Microglia & OGD/R model of BV2 cell line & $\begin{array}{l}\text { Opening } \mathrm{K}^{+} \text {-ATP channel; inhibiting the TLR4 } \\
\text { signaling pathway }\end{array}$ & [178] \\
\hline Curcumin & Macrophages & Mice BMDM & $\begin{array}{l}\text { Stopping } \mathrm{K}^{+} \text {efflux; inhibiting caspase- } 1 \text { activation } \\
\text { and IL-1 } \beta \text { secretion }\end{array}$ & {$[179]$} \\
\hline IVIG & $\begin{array}{l}\text { Neurons, primary } \\
\text { cortical neurons }\end{array}$ & $\begin{array}{l}\text { MCAO/R mice; OGD/R model of } \\
\text { neuron }\end{array}$ & $\begin{array}{l}\text { Increasing the expression level of the antiapoptotic } \\
\text { protein } \mathrm{BCl}-2\end{array}$ & {$[24,180]$} \\
\hline Aloe vera & $\begin{array}{l}\text { Macrophages } \\
\text { derived from } \\
\text { monocytes }\end{array}$ & & $\begin{array}{l}\text { Inhibiting specific signal transduction pathways and } \\
\text { proinflammatory cytokines }\end{array}$ & [181] \\
\hline A151 & $\begin{array}{l}\text { Macrophage derived } \\
\text { from bone marrow }\end{array}$ & BMDM OGD model & $\begin{array}{l}\text { Downregulating the levels of iNOS and NLRP3 } \\
\text { inflammasome }\end{array}$ & [182] \\
\hline Chrysophanol & Neurons & tMCAO mice & $\begin{array}{l}\text { Inhibiting the expression of NLRP3, caspase-1, and } \\
I_{L}-1 \beta\end{array}$ & [183] \\
\hline Umbelliferone & Neurons & MCAO rats & Reducing TXNIP expression & [172] \\
\hline Apocynin & $\begin{array}{l}\text { Neurons, Astrocytes, } \\
\text { Microglia }\end{array}$ & $\begin{array}{l}\text { MCAO/R model, astrocyte, BV2 cell } \\
\text { line }\end{array}$ & $\begin{array}{l}\text { Inhibiting the phosphorylation and degradation of } \\
\mid \mathrm{KBa} \text { and nuclear translocation of NF-KBp65 }\end{array}$ & [184] \\
\hline IFN- $\beta$ & Neurons & $\begin{array}{l}\text { tMCAO in IFN- } \beta \text { knockout (IFN- } \beta \\
\text { KO) mice }\end{array}$ & Inhibiting the STAT1 phosphorylation & [185] \\
\hline JQ1 & $\begin{array}{l}\text { Neurons, Astrocytes, } \\
\text { Microglia }\end{array}$ & $\begin{array}{l}\text { MCAO/R model, astrocyte, BV2 cell } \\
\text { line }\end{array}$ & BRD4 inhibitor; inhibiting NF-KB & [186] \\
\hline Meisoindigo & Neurons, Microglia & $\begin{array}{l}\text { MCAO mice stroke model, OGD/R } \\
\text { models of HT- } 22 \text { and BV2 cell lines }\end{array}$ & Suppressing the TLR4/NF-KB signaling pathway & [187] \\
\hline Ezetimibe & Neurons, Microglia & MCAO rats & $\begin{array}{l}\text { Increasing the expression of p-AMPK, Nrf2, and Ho-1 } \\
\text { and decreasing that of TXNIP }\end{array}$ & [188] \\
\hline Edaravone & Neurons, Microglia & Rats ICH & $\begin{array}{l}\text { Reducing the generation of IL-1 } \beta \text {, caspase- } 1 \text { and } \\
\text { inhibiting NF-KB }\end{array}$ & [189] \\
\hline $\begin{array}{l}\text { Ginkgo diterpene } \\
\text { lactones }\end{array}$ & $\begin{array}{l}\text { Neurons, Astrocytes, } \\
\text { Microglia }\end{array}$ & $\begin{array}{l}\text { MCAO/R mice, Primary astrocyte } \\
\text { OGD/R model }\end{array}$ & Downregulating of TLR4/NF-KB signaling & [190] \\
\hline $\begin{array}{l}\text { Ketone metabolite } \\
\text { hydroxybutyrate }\end{array}$ & & BMDM & Inhibiting $\mathrm{K}^{+}$outflow & [191] \\
\hline Probenecid & Astrocytes & Primary astrocyte OGD/R model & Pannexin 1 inhi201caspase- 1 and AQP4 & [192] \\
\hline
\end{tabular}


Table 2 Cell categories of drugs acting on and related effect/pathways after ischemic stroke (Continued)

\begin{tabular}{|c|c|c|c|c|}
\hline & Categories & Models & Effects/pathways & References \\
\hline $\begin{array}{l}\text { Nafamostat } \\
\text { mesilate }\end{array}$ & Microglia & tMCAO rats & $\begin{array}{l}\text { Inhibiting the NF-KB signaling pathway and inflam- } \\
\text { masome activation }\end{array}$ & [193] \\
\hline $17 \beta$-estradiol & Neurons & MCAO/R mice & $\begin{array}{l}\text { Reducing the expression of components of the } \\
\text { NLC4 inflammasome }\end{array}$ & [194] \\
\hline Procyanidins & Neurons, Microglia & $\begin{array}{l}\text { OGD/R and MCAO/R rats, BV2 cell } \\
\text { line }\end{array}$ & Inhibiting TLR4-NF-KB-NLRP3 signaling pathways & [195] \\
\hline Astragaloside IV & Neurons, Microglia & tMCAO/R mice & Inhibiting TLR4 pathway; reducing ROS production & [196] \\
\hline Resveratrol & Neurons & $\mathrm{MCAO} / \mathrm{R}$ rats & $\begin{array}{l}\text { Downregulating TXNIP expression; decreasing } \\
\text { autophagic activity }\end{array}$ & {$[84,197]$} \\
\hline Sulforaphane & Neurons & $\mathrm{MCAO} / \mathrm{R}$ rats & $\begin{array}{l}\text { Inhibiting NLRP3 inflammasome activity; } \\
\text { downregulating the expression of caspase-1, IL-18, } \\
\text { and IL-1 }\end{array}$ & [198] \\
\hline
\end{tabular}

MNS, 3,4-methylenedioxy-beta-nitrostyrene; IVIG, intravenous immunoglobulin; IFN- $\beta$, interferon- $\beta$; $p M C A O$, permanent middle cerebral artery occlusion; $t M C A O$, transient middle cerebral artery occlusion; $M C A O / R$, middle cerebral artery occlusion/reperfusion; $O G D / R$, oxygen glucose deprivation/reperfusion; $I C H$, intracerebral hemorrhage; BMDM, bone marrow-derived Macrophages; $\mathrm{K}^{+}$-ATP channel, ATP-sensitive potassium channel; iNOS, inducible nitric oxide synthase; STAT1, signal transducers and activators of transcription 1; BRD4, bromodomain-containing protein 4; $A Q P 4$, aquaporin 4 ; $C K L F 1$, chemokine-like factor 1 ; GPR40, G proteincoupled receptor 40; $A M P K$, adenosine monophosphate-activated protein kinase; LPS, lipopolysaccharide; TLR4, Toll-like recepetor; IL-1 $\beta$, interleukin-1 $\beta$; TXNIP, thioredoxin-interaction protein; NF-KB, nuclear factor kappa $\mathrm{B}$; $R O S$, reactive oxygen species

prevents activation of the NLRP3 receptor in mouse macrophages $[42,200]$. In addition, a study has reported that glibenclamide inhibits the NLRP3 inflammasome and effectively reduces edema development [201]. Moreover, nicorandil, an ATP-sensitive $\mathrm{K}^{+}$channel $\left(\mathrm{K}^{+}\right.$ATP) opener, inhibits the TLR4 signaling pathway and NLRP3 inflammasome activation, thereby reducing IL-1 $\beta$ production. In in vitro experiments, nicorandil has been shown to inhibit inflammasome activation and TLR4 signal transduction to combat oxygen-glucose deprivation (OGD)-induced neuroinflammation [178]. However, the roles of various $\mathrm{K}^{+}$channels in the treatment of stroke still need to be explored in more detail. 3,4-Methylenedioxy- $\beta$-nitrostyrene (MNS) has been shown to specifically stop NLRP3-induced ASC speck formation and oligomerization, but it does not block the $\mathrm{K}^{+}$flow induced by NLRP3 agonism. Moreover, NLRP3 ATPase activity can be inhibited by the administration of MNS in vitro, indicating that MNS blocks the NLRP3 inflammasome to alleviate the inflammatory response [168]. Parthenolide and Bay 11-7082 directly inhibit activation of the protease caspase- 1 to inhibit the various inflammasomes in macrophages [167]. Omega-3 fatty acids also arrest the NLRP3 inflammasome-dependent inflammatory response [169]. A randomized controlled study has shown that immediate administration of atorvastatin after atherosclerotic ischemic stroke significantly reduces the activation of immune inflammation in the acute phase of stroke [202]. The results of an experimental study have suggested that geniposide might reduce inflammatory cytokine levels and inhibit NLRP3 inflammasome activation by increasing the autophagic activity of the BV2 microglial cell line, thus reducing the inflammatory response after stroke [173]. Corylin inhibits NLRP3 inflammasome activation and alleviates lipopolysaccharide (LPS)-induced inflammation in LPS-activated BV2 cells [175]. Curcumin, a common suppressor of NLRP3 inflammasome activation, inhibits NLRP3 by stopping $\mathrm{K}^{+}$efflux and interfering with downstream events, which in turn inhibits caspase- 1 activation and IL-1 $\beta$ secretion [179]. Some drugs can indirectly inhibit NLRP3 inflammasome activation through molecular mediation and thus inhibit downstream inflammatory cytokines. In a standard rat model of cerebral ischemia, IMM-H004 (a novel coumarin derivative) has been found to provide significant protection against cerebral ischemia via an anti-inflammatory pathway dependent on chemokinelike factor 1 (CKLF1). IMM-H004 downregulates the binding of CKLF1 to C-C chemokine receptor type 4, further inhibiting NLRP3 inflammasome activation and the subsequent inflammatory response and ultimately protecting against ischemic damage. This evidence provides support for human clinical trials studying IMMH004 for the treatment of acute cerebral ischemia [171]. Arctigenin (ARC) therapy effectively inhibits the activation of the NLRP3 inflammasome and prevents the secretion of IL-1 $\beta$ and IL-18 caused by ischemic stroke in vivo and in vitro. The effects of administration of a specific silent information regulator 1 (sirtuin-1/sirt-1) inhibitor, EX527, prove that ARC protects against cerebral ischemia by inhibiting activation of the NLRP3 inflammasome in a sirtuin-1-dependent manner [177]. After $1 \mathrm{~h}$ of ischemia-reperfusion, minocycline can stop microglial activation and weaken damage caused by middle cerebral artery occlusion (MCAO) by inhibiting NLRP3 inflammasome activation and proinflammatory cytokine maturation/release, ameliorating neurological disorders, reducing infarct volumes, decreasing cerebral 
edema, and relieving ischemic brain injury [176]. Sinomenine (SINO) inhibits the NLRP3 inflammasome via the adenosine monophosphate-activated protein kinase (AMPK) pathway, thus exerting a neuroprotective effect in ischemic stroke by alleviating cerebral infarction, cerebral edema, neuronal apoptosis, and neurological impairment after MCAO [174]. NRF2 functions at the initiation step to downregulate ROS-induced activation of the NLRP3 inflammasome. Isoliquiritigenin inhibits NLRP3 inflammasome activation mediated by ROS and NF- $\mathrm{kB}$ by promoting the antioxidant system of NRF2 and alleviates early brain damage after hemorrhage [78, 170]. Eicosapentaenoic acid (EPA) suppresses NLRP3 inflammasome activation by obstructing $G$ proteincoupled receptor 40 (GPR40) and G protein-coupled receptor 120 (GPR120); importantly, EPA can ameliorate apoptosis induced by acute cerebral infarction [203].

\section{Treatments targeting expression at the transcriptional or translational stage}

In addition to treatments targeting gene expression products, there are also some small molecules or drugs that act on gene expression processes to regulate inflammatory responses by upregulating or downregulating the expression of various downstream proteins. In ischemic stroke models, treatment with intravenous immunoglobulin (IVIG) has been found to reduce neuronal cell death and infarct volume and to ameliorate brain function. In these models, IVIG increases the expression level of the antiapoptotic protein BCL-2, which inhibits the NLRP3 receptor by blocking binding between ATP and the NACHT domain in the NLRP3 receptor, downregulates proinflammatory cytokine expression, and protects neurons and cerebral tissue [24, 180]. A151 (a synthetic oligodeoxynucleotide containing multiple distal TTAGGG sequences) decreases maturation of IL-1 $\beta$ and caspase- 1 , reduces the generation of IL- $1 \beta$, downregulates the levels of inducible nitric oxide synthase (iNOS) and NLRP3, and inhibits depolarization of the intracellular mitochondrial membrane potential in activated myeloid-derived macrophages stimulated with OGD and LPS [182]. In the ischemic cerebral cortex, NADPH and apocynin inhibit phosphorylation and degradation of I $\mathrm{B} \alpha$; nuclear translocation of NF- $\kappa \mathrm{Bp} 65$; expression of NF-кBp65 targets, such as iNOS and cyclooxygenase (COX2); and expression of inflammasome proteins, including NLRP3, ASC, and caspase-1. These effects have been found to greatly decrease infarct size in a mouse stroke model, increase survival after stroke, restore neurological function, and provide relatively strong neuroprotective effects during ischemic stroke [184]. Chrysophanol, an extract of rhubarb, has a variety of pharmacological effects, including anti-inflammatory effects. In a transient MCAO (tMCAO) mouse model, chrysophanol has been shown to inhibit the expression of NLRP3, caspase-1, and IL-1 $\beta$ and to protect against ischemic brain injury [183]. Umbelliferone (UMB) therapy reduces TXNIP expression, inhibits NLRP3 inflammasome activation, and has a beneficial neuroprotective effect against focal cerebral ischemia [172]. Ezetimibe (Eze) increases the expression of p-AMPK, NRF2, and Ho-1 and decreases that of TXNIP, NLRP3, caspase-1, and IL-1 $\beta$, thus inhibiting oxidative stress and subsequent neuroinflammation to protect brain tissues. In addition, ruscogenin inhibits IL-1 $\beta$, NLRP3, caspase-1, and TXNIP expression; reduces ROS production; blocks MAPK pathway activity; relieves edema in the cerebral obstruction area; improves impairments in neurological function; increases cerebral blood flow (CBF); alleviates histopathological injury; and upregulates tight junction component expression. These findings provide a new perspective for the therapy of ischemic stroke [188]. Meisoindigo, a derivative of indirubin, significantly inhibits NLRP3 inflammasome activation and blocks the M1 polarization of microglia/macrophages by suppressing the TLR4/NF- $k B$ signaling pathway in a dosedependent manner, thus reducing ischemic brain injury caused by stroke [187]. Ginkgo diterpene lactones (GDLs) inhibit platelet aggregation, astrocyte activation, and proinflammatory cytokine release, which may be positively related to the downregulation of TLR4/NF- $\mathrm{kB}$ signaling [190]. The channel pannexin 1 can activate inflammasomes in astrocytes and participate in the process of ischemic injury. Probenecid, a pannexin 1 inhibitor, reduces the expression levels of NLRP3, caspase1 , and aquaporin 4 (AQP4) in OGD astrocyte models and inhibits IL- $1 \beta$ release; probenecid contributes to a neuroprotective effect against ischemic damage by inhibiting inflammasome activity and reducing astrocyte edema [192]. Nafamostat mesilate (NM) is a broadspectrum serine protease inhibitor. Administration of NM leads to inhibition of proinflammatory mediators and promotion of anti-inflammatory mediators; these effects may be partly attributable to the immunoregulatory effects of NM, which involve NF-kB signaling pathway inhibition and inflammasome activation [193]. Aloe vera (an immunomodulator) dose-dependently inhibits the production of pro-IL-1 $\beta$, caspase-1, NLRP3, and P2X7R by inhibiting specific signal transduction pathways and reduces the release of IL- 8 , TNF- $\alpha$, IL- 6 , and IL- $1 \beta$ in primary macrophages induced by LPS [181]. 17Estradiol remarkably reduces the expression of components of the NLRC4 inflammasome, AIM2, ASC, NLRP3, IL-1 $\beta$, IL-18, TNF- $\alpha$, and P2X7R at the gene and protein levels after global cerebral ischemia (GCI) [194]. Limiting inflammation after stroke has been documented to reduce neuronal death or improve nerve function, and IFN- $\beta$ has been recommended as a 
candidate for stroke treatment. As IFN- $\beta$ signaling weakens inflammation and mediates peripheral immune cell activity, it may positively affect stroke outcomes [185]. Studies have suggested that IFN- $\beta$ may inhibit IL$1 \beta$ production partly by inhibiting phosphorylation of the transcription factor signal transducer and activator of transcription 1 (STAT1), thereby inhibiting the NLRP3 inflammasome and caspase-1-dependent IL-1 $\beta$ maturation; thus, IFN- $\beta$ targeting might be a new approach to alleviate ischemic injury [204]. JQ1, a bromodomain-containing protein 4 (BRD4) inhibitor, can reduce the generation of proinflammatory agents by inhibiting NF- $\mathrm{kB}$, pyroptosis, and inflammasome activation, as shown by significantly reduced NLRP3, ASC, caspase-1, and GSDMD levels in MCAO mice; these effects can reduce infarct volumes, brain water content and neural function defects in MCAO mice and protect against brain injury induced by cerebral ischemia [186]. Moreover, edaravone reduces NLRP3 expression in microglia. Additionally, edaravone has neuroprotective effects similar to those of MCC950 and reduces the generation of IL- $1 \beta$, caspase- 1 , and NF- $\mathrm{kB}$ at the protein or gene level, significantly alleviating cerebral edema and improving neurological deficits in rats after cerebral hemorrhage [189]. Another molecule, the ketone metabolite $\beta$-hydroxybutyrate (BHB), exerts an antiinflammatory effect by inhibiting $\mathrm{K}^{+}$outflow from macrophages and reducing ASC oligomerization and speck formation, thereby inhibiting the generation of IL- $1 \beta$ and IL-18 in human mononuclear cells induced by NLRP3-induced ASC oligomers [191].

\section{Treatments targeting gene expression processes and products}

miR-223 inhibits activation of the NLRP3 inflammasome and generation of IL-1 $\beta$ by binding to three conserved sites in the untranslated region (UTR), thereby inhibiting protein expression [205-207], and downregulation of caspase-1 and IL-1 $\beta$ expression reduces brain edema and improves nerve function [208]. miR-155-5p targets DUSP14 to promote cerebral IRI by regulating the NF$\mathrm{KB}$ and MAPK signaling pathways, and inhibition of miR-155-5p is significantly effective in treating injured brain tissue. Therefore, research suggests that miR-155$5 \mathrm{p}$ may be a new target for ischemic stroke therapy [209]. Overexpression of miR-216a inhibits Janus tyrosine kinase 2 (JAK2) protein levels in OGD/reoxygenation $(\mathrm{OGD} / \mathrm{R})$-subjected neurons and ischemic areas in MCAO models, negatively regulates JAK and JAK2/ STAT3 pathways, reduces ischemic infarction incidence, and alleviates neurofunctional impairment [210]. miR19a-3p promotes I/R-induced inflammation and apoptosis by targeting insulin-like growth factor binding protein 3 (IGFBP3), as demonstrated by the finding that
miR-19a-3p inhibitors exert protective effects against cerebral IRI by inhibiting apoptosis and reducing inflammation, ultimately reducing infarct volume and improving nerve function and activity [211]. Knockdown of miR-155 expression reduces the severity of IRI by inhibiting the inflammatory response and improving neurological function, and miR-155 downregulation reduces OGD-induced injury by increasing proliferation, inhibiting apoptosis, and inhibiting inflammatory factor (TNF$\alpha$, IL-1 $\beta$, IL-6, iNOS, and COX-2) expression [212, 213]. miR-874-3p negatively regulates BCL-2-modifying factor (BMF) and BCL-2 family proteins to reduce the severity of ischemic injury [214]. Other miRNAs, including miRNA-133a-1 and miRNA-377, are also involved in NLRP3 inflammasome activation [215, 216]. In summary, different miRNAs have different effects on NLRP3 inflammasome activation and stroke outcome. Reducing miR-155-5p, miR-19a-3p, miR-155, miRNA-133a-1 and miRNA-377 levels may be of great value in treating inflammation associated with ischemic stroke. In contrast to these miRNAs, miR-223, miR-216a, and miR-874-3p suppress NLRP3 inflammasome activation and have beneficial effects. Procyanidins significantly inhibit in vivo and in vitro activation of $\mathrm{MCAO} /$ reperfusion (MCAO/R)- and OGD/R-mediated TLR4-NF-kB-NLRP3 signaling pathways; inhibit IL- $1 \beta$ production; significantly improve neurological deficits; and reduce cerebral edema, cerebral infarct size, and apoptosis [195]. In addition to miRNAs, a few compounds can also act on both gene expression processes and gene expression products related to NLRP3 inflammasome activation to influence ischemic brain injury. For example, astragaloside IV reduces the expression of TLR4 and its downstream adaptor proteins, including MyD88, Toll/ IL-1 $\beta$ receptor domain-containing adaptor-inducing interferon- $\beta$ (TRIF), and tumor necrosis factor receptorassociated factor 6 (TRAF6), thereby inhibiting NF- $\mathrm{kB}$ phosphorylation, reducing ROS production and in turn inhibiting NLRP3 activation [196]. Resveratrol downregulates TXNIP expression; reduces poly-ADP-ribose polymerase (PARP) activity; decreases autophagic activity; and inhibits NLRP3 activation, caspase-1 activation, and IL-1 $\beta$ release to significantly reduce cerebral infarct volume [84, 197]. Moreover, sulforaphane inhibits NLRP3 inflammasome activation and downregulates caspase-1, IL-18, and IL-1 $\beta$ expression, which improves prognosis after focal cerebral ischemia and consequently alleviates brain injury [198].

\section{Treatments involving stem cells and biological products}

After cerebral ischemia occurs, immune system activation, gene expression profile alteration, BBB destruction, immune cell infiltration, and cytokine production also occur. These events indicate that immune cells and even 
stem cells are important in ischemic stroke. Application of stem cells to control the immune-inflammatory response is a new treatment approach for ischemic stroke. Human cord blood-derived multipotent stem cells (HCB-SCs) cocultured with lymphocytes promote regulatory T cell (Treg) differentiation. Cocultured cell transplantation reduces the expression of NLRP3 and related factors, blocks activation of the NLRP3 inflammasome in neurons, suppresses the activity of NF- $\mathrm{kB}$ and extracellular signal-regulated kinase (ERK) in ischemic brain tissues, significantly improves nerve function defects, and reduces ischemic brain damage, indicating that this approach may be a promising treatment strategy for ischemic stroke [217]. Moreover, mesenchymal stem cell (MSC) therapy significantly reduces JNK phosphorylation induced by ischemia, showing that this treatment has antiapoptotic and anti-inflammatory effects [218]. In addition, experiments have shown that Tregs may have a neuroprotective role in ischemic stroke by inhibiting inflammation and effector T cell activation [219]. IL-33 can activate Tregs, which produces a neuroprotective effect related to reductions in apoptosis-related protein expression as well as generation and activation of St2dependent Tregs and Treg-related cytokines [220]. Research has shown that autologous bone marrow MSCs have lower immunogenicity and produce weaker immune responses than allogeneic bone marrow MSCs and can better promote recovery and reduce infarct volume in MCAO rats [221]. Nonhematopoietic umbilical blood stem cells (nh-UCBSCs) have also been demonstrated to protect ischemic brain tissues by inhibiting immune cells from undergoing peripheral migration into the brain or by downregulating abnormal activation of immune responses [222]. nh-UCBSCs have shown enormous potential in stroke treatment and exhibit an enhanced therapeutic window; these cells also have no known side effects and can be stored, and their production can be scaled for extensive use in stroke treatment [223].

\section{Other treatments}

In one study, MTS510 (an anti-TLR4 antibody) was administered through different routes in vivo to study MCAO in adult male wild-type mice (tMCAO range: 45 minutes to 2 days); the results showed that intravascular administration of MTS510 to mice subjected to $45 \mathrm{mi}-$ nutes of MCAO increased neurological function, decreased infarct volume, and reduced brain swelling, suggesting that blocking TLR4 by using specific monoclonal antibodies is a promising stroke treatment strategy [224]. In MCAO mouse models, activation of GPR120 protects against focal ischemic brain injury by preventing inflammation and apoptosis [225]. In vivo results have shown that notoginseng leaf triterpene (PNGL) pretreatment significantly reduces infarct size, decreases brain water content, and improves nerve function in $\mathrm{MCAO} / \mathrm{R}$ model rats. In addition, PNGL pretreatment significantly reduces $\mathrm{BBB}$ damage; inhibits neuronal apoptosis and neuronal loss caused by cerebral IRI; and significantly reduces the serum concentrations of IL-6, TNF- $\alpha$, IL-1 $\beta$, and HMGB1 in a dose-dependent manner. These findings suggest that inhibition of inflammation, which may be associated with MAPK inhibition and NF- $\mathrm{kB}$ activation, may be involved in the neuroprotective effect of PNGL [226]. In a rat model of MCAO, hispidulin has been found to improve neurological symptoms after cerebral IRI, thereby reducing the infarct area and cerebral edema. Hispidulin plays a neuroprotective role by modulating AMPK/glycogen synthase kinase (GSK) 3 signaling to inhibit NLRP3-mediated pyroptosis in vitro and in vivo [227].

\section{Expectations}

The brain is a complex organ with various components that engage in crosstalk to form a network that affects the brain itself. The NLRP3 inflammasome is responsible for exerting adverse effects on neurons after ischemic stroke. In addition to inflammasomes, ERS, autophagy, ferroptosis, oxidative stress, and other excessive physiological and pathological processes that are closely related to the NLRP3 inflammasome cause neuronal death. The ER is an organelle that regulates protein folding homeostasis by folding and modifying secretory and membrane proteins [228]. Exposure of cells to various stress signals disrupts ER homeostasis and causes dysfunction. Upon reception of stress signals, the ER triggers a protective or adaptive response known as the unfolded-protein response (UPR) in order to recover ER stability. However, severe ERS induces mitochondrial $\mathrm{Ca}^{2+}$ overload, $\mathrm{ROS}$ accumulation, and ATP depletion, thereby activating mitochondrial-dependent apoptosis [229, 230]. In addition, misfolded/abnormal proteins in cells trigger the UPR pathway, which may result in severe loss of neuronal function and viability [231]. ERS and oxidative stress jointly lead to activation of the NLRP3 inflammasome in neurons, causing inflammatory responses [232]. Inhibiting NLRP3 activation induced by ERS can protect neurons from ischemic injury and thus exert a neuroprotective effect after stroke [233, 234]. However, NLRP3 is involved in ERS-induced mitochondrial damage; thus, the NLRP3 inflammasome can also induce ERS, forming a feedback loop that further promotes inflammation $[235,236]$.

Autophagy is a physiological destruction process that differs from necrosis and apoptosis. The main characteristic of autophagy is the formation of autophagosomes. Upon encountering a series of stress conditions, cells attempt to maintain a stable intracellular environment and normal cell function by degrading cytoplasmic 
components [237, 238]. Stroke results in the production and activation of many stress factors, including ROS, as well as misfolding and abnormal accumulation of proteins. These factors induce autophagy [239, 240]. In addition, ERS can directly activate autophagy. Through autophagy, abnormal proteins are destroyed in lysosomal-dependent pathways to restore homeostasis [241]. Activated autophagy negatively regulates activation of the NLRP3 inflammasome. Conversely, autophagy dysfunction can lead to activation of the NLRP3 inflammasome, and inhibiting GSK-3 $\beta$ to enhance autophagy can inhibit NLRP3 inflammasome activation and reduce IRI $[242,243]$. Autophagy function is impaired after ischemic brain injury, but progesterone and geniposide can inhibit the activation and expression of the NLRP3 inflammasome and increase autophagic activity $[173,243]$. These results indicate that autophagy can negatively regulate the activation of the NLRP3 inflammasome. However, autophagy is a double-edged sword; it can not only play a neuroprotective role but also induce the NLRP3 inflammasome cascade through its overactivation resulting from excessive ER initiation, excessive ROS production and subsequent NLRP3 inflammasome activation [244]. Inhibition of autophagy or knockout of autophagy genes, such as LC3, results in inactivation of the NLRP3 inflammasome [245]. Autophagy regulates the activation of the NLRP3 inflammasome, and vice versa [246, 247]. For example, on the one hand, the occurrence of autophagy is dependent on the NLRP3 inflammasome sensor, so the NLRP3 inflammasome can activate autophagy [248]. On the other hand, the NLRP3 inflammasome commonly inhibits activation and diminishes the neuroprotective effect of autophagy through mature caspase-1-mediated cleavage of TRIF, a vital molecule in the TLR4-TRIF signaling pathway, which mediates autophagy activation [247, 249, 250].

Ferroptosis is a newly discovered form of $\mathrm{Fe}^{2+}$ dependent cell death that can lead to programmed neuronal death. Ferroptosis is induced by cellular redox imbalance, inhibition of glutathione peroxidase 4 (GPX 4) activity, and ultimate accumulation of lipid peroxides, which induces damage to cell structure and function and leads to cell death [251-253].

ERS and autophagy, through NLRP3 inflammation, influence the death of neurons after stroke and together act on cells to produce comprehensive and complex effects. Whether ferroptosis causes neuronal death through the NLRP3 inflammasome is unclear. Autophagy can induce ferroptosis by interfering with cellular iron homeostasis and by enhancing lipid peroxide and ROS generation, and autophagy simultaneously activates the NLRP3 inflammasome. Does ferroptosis induce NLRP3 inflammasome activation, or do these processes interact? Ferroptosis is a kind of iron accumulation- and ROS-dependent cell death, and ROS production is a nonnegligible mechanism of NLRP3 inflammasome activation. NLRP3 inflammasome activation is accompanied by ferroptosis [254], and antioxidants or inhibitors of ferroptosis can inhibit the NLRP3 inflammasome [255]. It has also been documented that myrrh exerts a neuroprotective effect by regulating the TXNIP/NLRP3 axis in ischemic stroke to reduce ROS-mediated ferroptosis [256]. Therefore, we hypothesize that activation of the NLRP3 inflammasome may be related to ferroptosis and that these processes may engage in crosstalk. However, more research is needed to test this hypothesis. We propose that various effects in the body interact with each other to form a lethal network of neurons after stroke (LNAS) (Fig. 4). It is possible that no drugs with satisfactory clinical effects have been found so far because the existing drugs act only on a single site, neglecting the complexity of the physiological regulatory network and the neuronal death network after stroke. This possibility emphasizes that each organism should be considered as a whole, that various factors should be comprehensively assessed, and that more attention should be paid to the relationships among different aspects in future research.

\section{Conclusion}

Recent studies have identified NLRP3 inflammasomemediated ischemic stroke as a new mechanism that leads to neuron and glial cell death after brain injury. This inflammatory mechanism, which involves the innate immune system, not only causes brain tissue damage but also plays a beneficial role in brain tissue recovery. After cerebral vascular obstruction or thromboembolism, cerebral tissue is damaged due to ischemia and hypoxia, and cell stress reactions, including intracellular $\mathrm{K}^{+}$efflux, mitochondrial injury, high ROS production, lysosomal rupture, and increases in intracellular $\mathrm{Ca}^{2+}$ levels, occur. Through various channel components (such as P2X7R and TXNIP) and signaling pathways (the NF- $\mathrm{kB}$ and MAPK pathways), these changes activate NLRP3, leading to NLRP3-mediated cleavage and production of caspase1 from pro-caspase- 1 , which is followed by processing of pro-IL-1 $\beta$ and pro-IL-18 into mature inflammatory cytokines. Various components are involved in stress responses and the inflammatory process, and many drugs and molecules that inhibit the NLRP3 inflammasome and reduce the inflammatory response in the context of ischemic brain injury have been identified. The effectiveness of these agents has been demonstrated in several experiments, as described above. The brain is a complex 


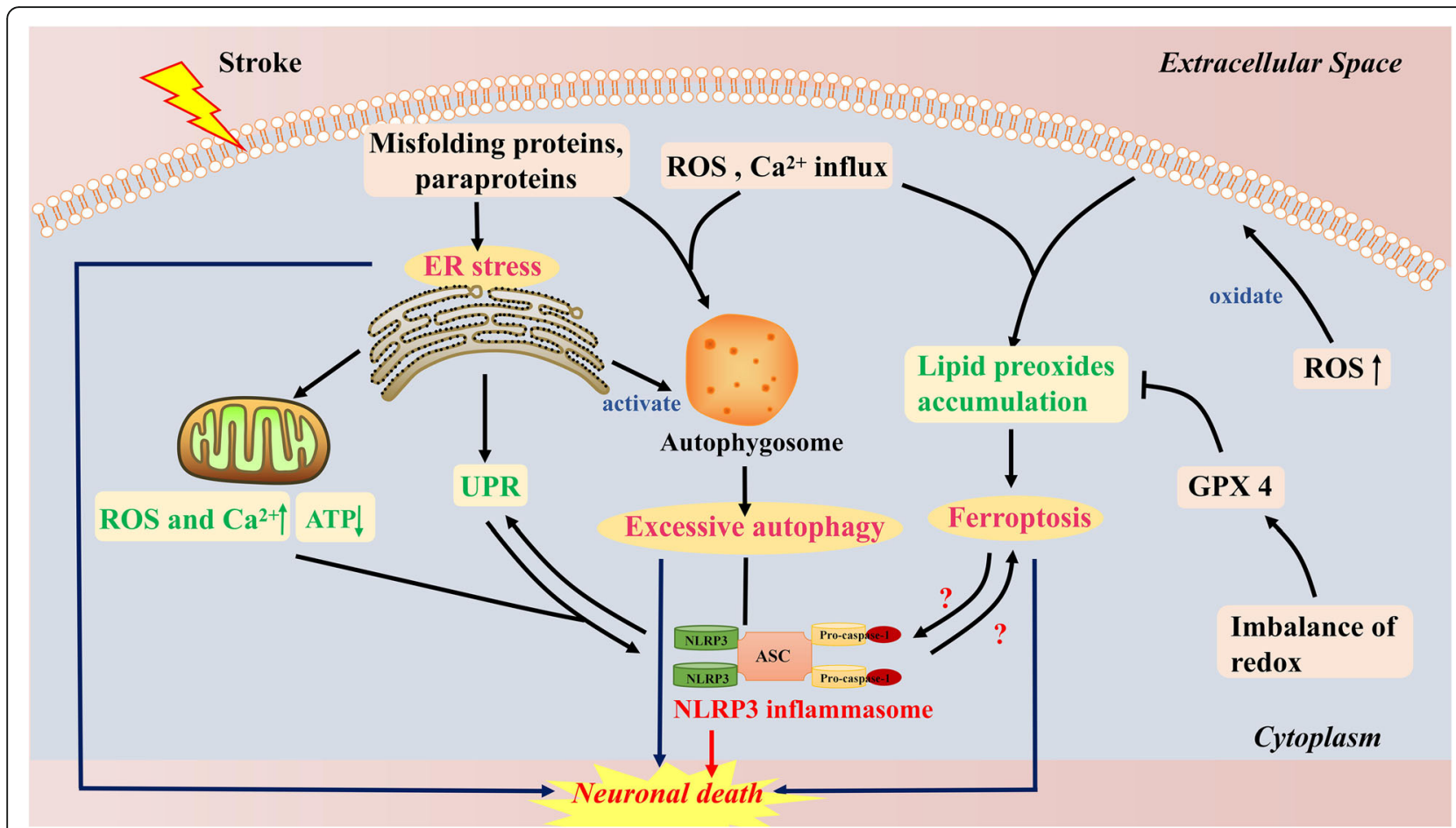

Fig. 4 Crosstalk among several physiological and pathological processes leads to neuronal death after stroke. Misfolded proteins and paraproteins trigger ER stress and the UPR to activate the NLRP3 inflammasome and aggravate inflammatory responses; the NLRP3 inflammasome can also promote the UPR and ER stress. ROS accumulation, $\mathrm{Ca}^{2+}$ dyshomeostasis, and ER stress excessively activate autophagy. Autophagy normally inhibits the NLRP3 inflammasome but can induce NLRP3 inflammasome activation when it is excessive. The NLRP3 inflammasome can also act on autophagy. Lipid peroxide accumulation results in ferroptosis, and there is probably crosstalk between ferroptosis and NLRP3 inflammasome activation. ER stress, excessive autophagy, ferroptosis, and the NLRP3 inflammasome together form an LNAS

organ, and its homeostasis is maintained by a complicated network of multifarious physiological and pathological mechanisms. Understanding the crosstalk of the NLRP3 inflammasome with other entities or mechanisms may be beneficial for the development of effective therapeutic strategies for ischemic stroke.

\section{Abbreviations}

ACE-2: Angiotensin-converting enzyme type 2; AIM2: Absent in melanoma 2; AMPK: Adenosine monophosphate-activated protein kinase; AngII: Angiotensin II; AQP4: Aquaporin 4; ARC: Arctigenin; ASC: Apoptosisassociated speck-like protein with a CARD; ASIC: Acid-sensitive ion channel; ATP: Adenosine triphosphate; BBB: Blood-brain barrier; BBG: Brilliant Blue G; BHB: $\beta$-Hydroxybutyrate; BMDM: Bone marrow-derived macrophage; BMF: BCL-2-modifying factor; BMI: Body mass index; BRD4: Bromodomaincontaining protein 4; C5aR2: Complement 5a receptor 2; CAMP: Cyclic adenosine monophosphate; $\mathrm{CaSR}: \mathrm{Ca}^{2+}$-sensing receptor; $\mathrm{CBF}$ : Cerebral blood flow; cGAMP: Cyclic GMP-AMP: cGAS: cGAMP synthase:

CGRP: Calcitonin gene-related peptide; CKLF1: Chemokine-like factor 1; CNS: Central nervous system; CoaC: Coagulation cascade;

ComC: Complement cascade; COX2: Cyclooxygenase 2; CRP: C-reactive protein; Cyt: Cytochrome-c; DAG: Diacylglycerol; DAMP: Damage-associated molecular pattern; dsRNA: Double-stranded RNA; EPA: Eicosapentaenoic acid; ER: Endoplasmic reticulum; ERK: Extracellular signal-regulated kinase; ESR: Erythrocyte sedimentation rate; Eze: Ezetimibe; GCl: Global cerebral ischemia; GDL: Ginkgo diterpene lactone; GPCR: G protein-coupled receptor; GPR120: GPCR 120; GPR40: GPCR 40; GPR6CA: GPCR family C group 6 member A; GSDMD: Gasdermin D; HCB-SC: Human cord blood-derived multipotent stem cell; HMGB1: High-mobility group box 1; I/R: Ischemia/ reperfusion; IGFBP3: Insulin-like growth factor-binding protein 3;
IL: Interleukin; iNOS: Inducible NOS; InsP3: Inositol triphosphate; IRI: I/R injury; IVIG: Intravenous immunoglobulin; JAK2: Janus tyrosine kinase 2; LDL-C: LoWdensity lipoprotein cholesterol; LNAS: Lethal network of neurons after stroke; LPS: Lipopolysaccharide; LRR: Leucine-rich repeat; MAC: Membrane attack complex; MAPK: Mitogen-activated protein kinase; MBL: Mannan-binding lectin; MCAO: Middle cerebral artery occlusion; MCU: Mitochondrial calcium uniporter; MNS: 3,4-Methylenedioxy- $\beta$-nitrostyrene; MSC: Mesenchymal stem cell; NACHT: NAIP, CIITA, HET-E and TP1: NADPH: Nicotinamide adenine dinucleotide phosphate; $\mathrm{NCX}: \mathrm{Na}^{+} / \mathrm{Ca}^{2+}$ exchanger; $\mathrm{NF}-\mathrm{kB}$ : Nuclear factor kappa B; nh-UCBSC: Nonhematopoietic umbilical blood stem cell; NLR: NODlike receptor; NLRP3: NLR family pyrin domain-containing 3; NM: Nafamostat mesilate; NMDAR: N-Methyl-D-aspartate receptor; NOD: Nucleotide-binding oligomerization domain; NOS: Nitric oxide synthase; NOX: NADPH oxidase; NRF2: Nuclear factor erythrocyte 2-related factor 2; OGD: Oxygen-glucose deprivation; P2X7R: Purinergic ligand-gated ion channel 7 receptor; PA: Palmitic acid; PAMP: Pathogen-associated molecular pattern; PARP: PolyADP-ribose polymerase; PIP2: Phosphatidylinositol-4,5-diphosphate; PKR: Protein kinase R; PLA2: Phospholipase A2; PLC: Phospholipase C; PNGL: Notoginseng leaf triterpene; PRR: Pattern recognition receptor; PYD: NTerminal pyrin domain; REC: Retinal endothelial cell; RIP1: Receptorinteracting protein 1; ROS: Reactive oxygen species; Sc-tPA: Single-chain form of tPA; SINO: Sinomenine; Sirtuin-1: Silent information regulator 1; SOCE: Store-operated $\mathrm{Ca}^{2+}$ entry; STAT1: Signal transducer and activator of transcription 1; TLR: Toll-like receptor; TLR4: Toll-like receptor 4; tMCAO: Transient MCAO; tPA: Tissue plasminogen activator; TRAF6: Tumor necrosis factor receptor-associated factor 6 ; TRIF: Toll/IL-1 $\beta$ receptor domaincontaining adaptor-inducing interferon- $\beta$; TRX: Thioredoxin; TXNIP: TRXinteracting protein; UMB: Umbelliferone; UTR: Untranslated region

Acknowledgements

Not applicable. 


\section{Authors' contributions}

Xu QX wrote the initial draft. Zhao B contributed to reviewing the literature. Ye YZ prepared the figures and submitted the article. Li YN and Zhang YG collected the literature and made the tables. Gu LJ and Xiong XX designed the manuscript and prepared the final version. The author(s) read and approved the final manuscript.

\section{Funding}

This study was supported by the National Natural Science Foundation of China (Nos. 82071339 and 81771283 to Lijuan Gu; No. 81901994 to Bo Zhao; No. 81870939 to Xiaoxing Xiong) and the Natural Science Foundation of Hubei Province (No. 2019CFB498 to Lijuan Gu).

\section{Availability of data and materials}

Not applicable.

\section{Declarations}

\section{Ethics approval and consent to participate}

Not applicable

\section{Consent for publication}

Not applicable

\section{Competing interests}

The authors declare that they have no competing interests.

\section{Author details}

'Central Laboratory, Renmin Hospital of Wuhan University, Wuhan 430060, China. ${ }^{2}$ Department of Anesthesiology, Renmin Hospital of Wuhan University, Wuhan 430060, China. ${ }^{3}$ Department of Neurosurgery, Renmin Hospital of Wuhan University, Wuhan 430060, China.

Received: 9 November 2020 Accepted: 24 March 2021

\section{Published online: 31 May 2021}

\section{References}

1. Katan M, Luft A. Global burden of stroke. Semin Neurol. 2018;38(2):208-11 https://doi.org/10.1055/s-0038-1649503.

2. Lapchak PA, Zhang JH. The high cost of stroke and stroke cytoprotection research. Transl Stroke Res. 2017;8(4):307-17 https://doi.org/10.1007/s12975016-0518-y.

3. Benjamin EJ, Virani SS, Callaway CW, Chamberlain AM, Chang AR, Cheng S, et al. Heart Disease and Stroke Statistics-2018 Update: a report from the American Heart Association. Circulation. 2018;137(12):e67-e492 https://doi. org/10.1161/CIR.0000000000000558.

4. Hata R, Maeda K, Hermann D, Mies G, Hossmann KA. Evolution of brain infarction after transient focal cerebral ischemia in mice. J Cereb Blood Flow Metab. 2000;20(6):937-46.

5. Fann DY, Lee SY, Manzanero S, Chunduri P, Sobey CG, Arumugam TV. Pathogenesis of acute stroke and the role of inflammasomes. Ageing Res Rev. 2013;12(4):941-66 https://doi.org/10.1016/j.arr.2013.09.004.

6. McAuley MA. Rodent models of focal ischemia. Cerebrovasc Brain Metab Rev. 1995;7(2):153-80.

7. Dichgans M, Pulit SL, Rosand J. Stroke genetics: discovery, biology, and clinical applications. Lancet Neurol. 2019;18(6):587-99 https://doi.org/10.101 6/S1474-4422(19)30043-2.

8. Donnan GA, Fisher M, Macleod M, Davis SM. Stroke. Lancet. 2008:371(9624): 1612-23 https://doi.org/10.1016/S0140-6736(08)60694-7.

9. Woodruff TM, Thundyil J, Tang SC, Sobey CG, Taylor SM, Arumugam TV. Pathophysiology, treatment, and animal and cellular models of human ischemic stroke. Mol Neurodegener. 2011;6(1):11 https://doi.org/10.1186/1 750-1326-6-11.

10. Famakin BM. The immune response to acute focal cerebral ischemia and associated post-stroke immunodepression: a focused review. Aging Dis. 2014;5(5):307-26 https://doi.org/10.14336/AD.2014.0500307.

11. Ma C, Liu S, Zhang S, Xu T, Yu X, Gao Y, et al. Evidence and perspective for the role of the NLRP3 inflammasome signaling pathway in ischemic stroke and its therapeutic potential (Review). Int J Mol Med. 2018;42(6):2979-90 https://doi.org/10.3892/ijmm.2018.3911.
12. Minutoli L, Puzzolo D, Rinaldi M, Irrera N, Marini H, Arcoraci V, et al. ROSmediated NLRP3 Inflammasome activation in brain, heart, kidney, and testis ischemia/reperfusion injury. Oxidative Med Cell Longev. 2016:2183026.

13. Ahmad M, Dar NJ, Bhat ZS, Hussain A, Shah A, Liu H, et al. Inflammation in ischemic stroke: mechanisms, consequences and possible drug targets. CNS Neurol Disord Drug Targets. 2014;13(8):1378-96 https://doi.org/10.2174/1 871527313666141023094720 .

14. Astrup J, Siesjö BK, Symon L. Thresholds in cerebral ischemia - the ischemic penumbra. Stroke. 1981;12(6):723-5 https://doi.org/10.1161/01.STR.12.6.723.

15. Manning NW, Campbell BCV, Oxley TJ, RJS C. Acute ischemic stroke: time, penumbra, and reperfusion. Stroke. 2014;45(2):640-4

16. Yoshimura S, Sakai N, Uchida K, Yamagami H, Ezura M, Okada Y, et al. Endovascular therapy in ischemic stroke with acute large-vessel occlusion: Recovery by Endovascular Salvage for Cerebral Ultra-Acute Embolism Japan Registry 2. J Am Heart Assoc. 2018;7(9)

17. Schwamm LH, Ali SF, Reeves MJ, Smith EE, Saver JL, Messe S, et al. Temporal trends in patient characteristics and treatment with intravenous thrombolysis among acute ischemic stroke patients at Get With The Guidelines-Stroke hospitals. Circ Cardiovasc Qual Outcomes. 2013:6(5):543-9 https://doi.org/10.1161/CIRCOUTCOMES.111.000095.

18. Taschner CA, Treier M, Schumacher M, Berlis A, Weber J, Niesen W. Mechanical thrombectomy with the Penumbra recanalization device in acute ischemic stroke. J Neuroradiol. 2011;38(1):47-52.

19. Parcq J, Bertrand T, Montagne A, Baron AF, Macrez R, Billard JM, et al. Unveiling an exceptional zymogen: the single-chain form of TPA is a selective activator of NMDA receptor-dependent signaling and neurotoxicity. Cell Death Differ. 2012;19(12):1983-91.

20. Ahmed N, Näsman P, Wahlgren NG. Effect of intravenous nimodipine on blood pressure and outcome after acute stroke. Stroke. 2000;31(6):1250-5 https://doi.org/10.1161/01.STR.31.6.1250.

21. Chan SA, Reid KH, Schurr A, Miller JJ, lyer V, Tseng MT. Fosphenytoin reduces hippocampal neuronal damage in rat following transient global ischemia. Acta Neuro. 1998;140(2):175-80 https://doi.org/10.1007/s00701 0050080.

22. Tang SC, Wang YC, Li Yl, Lin HC, Manzanero S, Hsieh YH, et al. Functional role of soluble receptor for advanced glycation end products in stroke. Arterioscl Thrombosis Vasc Biol. 2013;33(3):585-94 https://doi.org/10.1161/A TVBAHA.112.300523.

23. Tang SC, Arumugam TV, Xu X, Cheng A, Mughal MR, Jo DG, et al. Pivotal role for neuronal Toll-like receptors in ischemic brain injury and functional deficits. Proceed Natl Acad Sci U S A. 2007;104(34):13798-803 https://doi. org/10.1073/pnas.0702553104.

24. Fann DY, Lee SY, Manzanero S, Tang SC, Gelderblom M, Chunduri P, et al. Intravenous immunoglobulin suppresses NLRP1 and NLRP3 inflammasomemediated neuronal death in ischemic stroke. Cell Death Dis. 2013;4(9):e790 https://doi.org/10.1038/cddis.2013.326.

25. Tschopp J, Schroder K. NLRP3 inflammasome activation: the convergence of multiple signalling pathways on ROS production? Nat Rev Immunol. 2010; 10(3):210-5 https://doi.org/10.1038/nri2725.

26. Agostini L, Martinon F, Burns K, McDermott MF, Hawkins PN, Tschopp J. NALP3 forms an IL-1 beta-processing inflammasome with increased activity in Muckle-Wells autoinflammatory disorder. Immunity. 2004;20(3):319-25 https://doi.org/10.1016/S1074-7613(04)00046-9.

27. Sutterwala FS, Ogura Y, Szczepanik M, Lara-Tejero M, Lichtenberger GS, Grant EP, et al. Critical Role for NALP3/CIAS1/Cryopyrin in Innate and Adaptive Immunity through Its Regulation of Caspase-1. Immunity. 2006; 24(3):317-27 https://doi.org/10.1016/j.immuni.2006.02.004.

28. Franchi L, Warner N, Viani K, Nuñez G. Function of Nod-like receptors in microbial recognition and host defense. Immunol Rev. 2009;227(1):106-28 https://doi.org/10.1111/j.1600-065X.2008.00734.x

29. Martinon F, Burns K, Tschopp J. The inflammasome: a molecular platform triggering activation of inflammatory caspases and processing of prolL-beta. Mol Cell. 2002;10(2):417-26 https://doi.org/10.1016/S1097-2 765(02)00599-3.

30. Halle A, Hornung V, Petzold GC, Stewart CR, Monks BG, Reinheckel T, et al The NALP3 inflammasome is involved in the innate immune response to amyloid-3. Nat Immunol. 2008;9(8):857-65 https://doi.org/10.1038/ni.1636.

31. Hornung V, Bauernfeind F, Halle A, Samstad EO, Kono H, Rock KL, et al. Silica crystals and aluminum salts activate the NALP3 inflammasome through phagosomal destabilization. Nat Immunol. 2008;9(8):847-56 https://doi.org/1 0.1038/ni.1631. 
32. Liepinsh E, Barbals R, Dahl E, Sharipo A, Staub E, Otting G. The deathdomain fold of the ASC PYRIN domain, presenting a basis for PYRIN/PYRIN recognition. J Mol Biol. 2003;332(5):1155-63 https://doi.org/10.1016/j.jmb.2 003.07.007.

33. Broz P, von Moltke J, Jones JW, Vance RE, Monack DM. Differential requirement for CASPASE-1 autoproteolysis in pathogen-induced cell death and cytokine processing. Cell Host Microbe. 2010;8(6):471-83 https://doi. org/10.1016/j.chom.2010.11.007.

34. Franchi L, Eigenbrod T, Muñoz-Planillo R, Nuñez G. The inflammasome: a caspase-1-activation platform that regulates immune responses and disease pathogenesis. Nat Immunol. 2009;10(3):241-7 https://doi.org/10.1038/ni.1703.

35. Masumoto J, Taniguchi S, Ayukawa K, Sarvotham H, Kishino T, Niikawa N, et al. ASC, a novel 22-kDa protein, aggregates during apoptosis of human promyelocytic leukemia HL-60 cells. J Biol Chem. 1999;274(48):33835-8 https://doi.org/10.1074/jbc.274.48.33835.

36. Martinon F, Mayor A, Tschopp J. The inflammasomes: guardians of the body. Annu Rev Immunol. 2009;27(1):229-65 https://doi.org/10.1146/a nnurev.immunol.021908.132715.

37. Ye $X$, Shen $T$, Hu J, Zhang L, Zhang $Y$, Bao L, et al. Purinergic $2 X 7$ receptor/ NLRP3 pathway triggers neuronal apoptosis after ischemic stroke in the mouse. Exp Neurol. 2017;292:46-55 https://doi.org/10.1016/j.expneurol.2017. 03.002.

38. Swanson KV, Deng M, Ting JP. The NLRP3 inflammasome: molecular activation and regulation to therapeutics. Nat Rev Immunol. 2019;19(8):47789 https://doi.org/10.1038/s41577-019-0165-0.

39. Muñoz-Planillo R, Kuffa P, Martínez-Colón G, Smith BL, Rajendiran TM, Núñez G. $\mathrm{K}^{+}$efflux is the common trigger of NLRP3 inflammasome activation by bacterial toxins and particulate matter. Immunity. 2013;38(6):1142-53 https://doi.org/10.1016/j.immuni.2013.05.016.

40. Arlehamn CS, Pétrilli V, Gross O, Tschopp J, Evans TJ. The role of potassium in inflammasome activation by bacteria. J Biol Chem. 2010;285(14):10508-18 https://doi.org/10.1074/jbc.M109.067298.

41. Pétrilli V, Papin S, Dostert C, Mayor A, Martinon F, Tschopp J. Activation of the NALP3 inflammasome is triggered by low intracellular potassium concentration. Cell Death Differ. 2007;14(9):1583-9 https://doi.org/10.1038/sj. cdd.4402195.

42. Lamkanfi M, Mueller JL, Vitari AC, Misaghi S, Fedorova A, Deshayes K, et al. Glyburide inhibits the Cryopyrin/Nalp3 inflammasome. J Cell Biol. 2009; 187(1):61-70 https://doi.org/10.1083/jcb.200903124.

43. Schorn C, Frey B, Lauber K, Janko C, Strysio M, Keppeler H, et al. Sodium overload and water influx activate the NALP3 inflammasome. J Biol Chem. 2011;286(1):35-41 https://doi.org/10.1074/jbc.M110.139048.

44. Wilhelm K, Ganesan J, Müller T, Dürr C, Grimm M, Beilhack A, et al. Graftversus-host disease is enhanced by extracellular ATP activating P2X7R. Nat Med. 2010;16(12):1434-8 https://doi.org/10.1038/nm.2242.

45. de Rivero Vaccari JP, Bastien D, Yurcisin G, Pineau I, Dietrich WD, De Koninck $Y$, et al. P2X4 receptors influence inflammasome activation after spinal cord injury. J Neurosci. 2012;32(9):3058-66.

46. Silverman WR, de Rivero Vaccari JP, Locovei S, Qiu F, Carlsson SK, Scemes E, et al. The pannexin 1 channel activates the inflammasome in neurons and astrocytes. J Biol Chem. 2009;284(27):18143-51 https://doi.org/10.1074/jbc. M109.004804

47. Ferrari D, Pizzirani C, Adinolfi E, Lemoli RM, Curti A, Idzko M, et al. The P2X7 receptor: a key player in IL-1 processing and release. J Immunol. 2006;176(7): 3877-83 https://doi.org/10.4049/jimmunol.176.7.3877.

48. Lee GS, Subramanian N, Kim Al, Aksentijevich I, Goldbach-Mansky R, Sacks $D B$, et al. The calcium-sensing receptor regulates the NLRP3 inflammasome through Ca2+ and cAMP. Nature. 2012;492(7427):123-7 https://doi.org/10.1 038/nature11588.

49. Bano D, Young KW, Guerin CJ, Lefeuvre R, Rothwell NJ, Naldini L, et al. Cleavage of the plasma membrane $\mathrm{Na}+/ \mathrm{Ca} 2+$ exchanger in excitotoxicity. Cell. 2005;120(2):275-85 https://doi.org/10.1016/j.cell.2004.11.049.

50. Murakami T, Ockinger J, Yu J, Byles V, McColl A, Hofer AM, et al. Critical role for calcium mobilization in activation of the NLRP3 inflammasome. Proceed Natl Acad Sci U S A. 2012;109(28):11282-7 https://doi.org/10.1073/pnas.111 7765109.

51. Korff S, Riechert N, Schoensiegel F, Weichenhan D, Autschbach F, Katus HA, et al. Calcification of myocardial necrosis is common in mice. Virchows Arch. 2006:448(5):630-8 https://doi.org/10.1007/s00428-005-0071-7.

52. Rossol M, Pierer M, Raulien N, Quandt D, Meusch U, Rothe K, et al. Extracellular Ca2+ is a danger signal activating the NLRP3 inflammasome through G protein-coupled calcium sensing receptors. Nat Commun. 2012; 3(1):1329 https://doi.org/10.1038/ncomms2339.

53. Bos JL. Epac: a new CAMP target and new avenues in CAMP research. Nat Rev Mol Cell Biol. 2003:4(9):733-8 https://doi.org/10.1038/nrm1197.

54. Kim C, Cheng CY, Saldanha SA, Taylor SS. PKA-I holoenzyme structure reveals a mechanism for CAMP-dependent activation. Cell. 2007;130(6): 1032-43 https://doi.org/10.1016/j.cell.2007.07.018.

55. Peters-Golden M. Putting on the brakes: cyclic AMP as a multipronged controller of macrophage function. Sci Signal. 2009;2(75):pe37 https://doi. org/10.1126/scisignal.275pe37.

56. Hofer AM, Brown EM. Extracellular calcium sensing and signalling. Nat Rev Mol Cell Biol. 2003;4(7):530-8 https://doi.org/10.1038/nrm1154.

57. Khan MA, Conigrave AD. Mechanisms of multimodal sensing by extracellular $\mathrm{Ca}(2+)$-sensing receptors: a domain-based survey of requirements for binding and signalling. Br J Pharmacol. 2010;159(5):1039_ 50 https://doi.org/10.1111/j.1476-5381.2009.00603.x.

58. Feske S. Calcium signalling in lymphocyte activation and disease. Nat Rev Immunol. 2007;7(9):690-702.

59. Triantafilou K, Hughes TR, Triantafilou M, Morgan BP. The complement membrane attack complex triggers intracellular Ca2+ fluxes leading to NLRP3 inflammasome activation. J Cell Sci. 2013;126(13):2903-13.

60. Giladi M, Tal I, Khananshvili D. Structural features of ion transport and allosteric regulation in sodium-calcium exchanger (NCX) proteins. Front Physiol. 2016;7:30.

61. Pignataro G, Sirabella R, Anzilotti S, Di Renzo G, Annunziato L. Does $\mathrm{Na}^{+}$/ $\mathrm{Ca}^{2+}$ exchanger, NCX, represent a new druggable target in stroke intervention? Transl Stroke Res. 2014;5(1):145-55 https://doi.org/10.1007/s12 975-013-0308-8.

62. Pilitsis JG, Diaz FG, O'Regan MH, Phillis JW. Inhibition of $\mathrm{Na}(+) / \mathrm{Ca}(2+)$ exchange by KB-R7943, a novel selective antagonist, attenuates phosphoethanolamine and free fatty acid efflux in rat cerebral cortex during ischemia-reperfusion injury. Brain Res. 2001;916(1-2):192-8 https://doi.org/1 0.1016/S0006-8993(01)02896-7.

63. Morimoto N, Kita S, Shimazawa M, Namimatsu H, Tsuruma K, Hayakawa K, et al. Preferential involvement of $\mathrm{Na}^{+} / \mathrm{Ca}^{2+}$ exchanger type- 1 in the brain damage caused by transient focal cerebral ischemia in mice. Biochem Biophys Res Commun. 2012;429(3-4):186-90 https://doi.org/10.1016/j.bbrc.2 012.10.114.

64. Kattoor AJ, Pothineni NVK, Palagiri D, Mehta JL. Oxidative stress in atherosclerosis. Curr Atheroscler Rep. 2017;19(11):42 https://doi.org/10.1007/ s11883-017-0678-6.

65. Song J, Li J, Hou F, Wang X, Liu B. Mangiferin inhibits endoplasmic reticulum stress-associated thioredoxin-interacting protein/NLRP3 inflammasome activation with regulation of AMPK in endothelial cells. Metabolism. 2015;64(3):428-37 https://doi.org/10.1016/j.metabol.2014.11.008.

66. Turrens JF. Mitochondrial formation of reactive oxygen species. J Physiol. 2003:552(Pt 2):335-44 https://doi.org/10.1113/jphysiol.2003.049478.

67. Zhou R, Tardivel A, Thorens B, Choi I, Tschopp J. Thioredoxin-interacting protein links oxidative stress to inflammasome activation. Nat Immunol. 2010;11(2):136-40 https://doi.org/10.1038/ni.1831.

68. Ochoa CD, Wu RF, Terada LS. ROS signaling and ER stress in cardiovascular disease. Mol Asp Med. 2018;63:18-29 https://doi.org/10.1016/j.mam.2018.03.002

69. Friedman JR, Lackner $L$, West M, DiBenedetto JR, Nunnari J Voeltz GK. ER tubules mark sites of mitochondrial division. Science (New York, NY). 2011; 334(6054):358-62.

70. Zhou R, Yazdi AS, Menu P, Tschopp J. A role for mitochondria in NLRP3 inflammasome activation. Nature. 2011:469(7329):221-5 https://doi.org/10.1 038/nature09663.

71. Shimada K, Crother TR, Karlin J, Dagvadorj J, Chiba N, Chen S, et al. Oxidized mitochondrial DNA activates the NLRP3 inflammasome during apoptosis. Immunity. 2012:36(3):401-14 https://doi.org/10.1016/j.immuni.2012.01.009.

72. Kahles T, Kohnen A, Heumueller S, Rappert A, Bechmann I, Liebner S, et al. $\mathrm{NADPH}$ oxidase Nox1 contributes to ischemic injury in experimental stroke in mice. Neurobiol Dis. 2010;40(1):185-92 https://doi.org/10.1016/j.nbd.2010. 05.023.

73. Heeba GH, El-Hanafy AA. Nebivolol regulates eNOS and iNOS expressions and alleviates oxidative stress in cerebral ischemia/reperfusion injury in rats. Life Sci. 2012;90(11-12):388-95 https://doi.org/10.1016/j.lfs.2011.12.001.

74. Abramov AY, Scorziello A, Duchen MR. Three distinct mechanisms generate oxygen free radicals in neurons and contribute to cell death during anoxia and reoxygenation. J Neurosci. 2007;27(5):1129-38. 
75. Nakahira K, Haspel JA, Rathinam VA, Lee SJ, Dolinay T, Lam HC, et al. Autophagy proteins regulate innate immune responses by inhibiting the release of mitochondrial DNA mediated by the NALP3 inflammasome. Nat Immunol. 2011;12(3):222-30 https://doi.org/10.1038/ni.1980.

76. Sogawa Y, Nagasu H, Iwase S, Ihoriya C, Itano S, Uchida A, et al. Infiltration of $M 1$, but not $M 2$, macrophages is impaired after unilateral ureter obstruction in Nrf2-deficient mice. Sci Rep. 2017;7(1):8801 https://doi.org/1 0.1038/s41598-017-08054-2

77. Zhao C, Gillette DD, Li X, Zhang Z, Wen H. Nuclear factor E2-related factor-2 (Nrf2) is required for NLRP3 and AIM2 inflammasome activation. J Biol Chem. 2014;289(24):17020-9 https://doi.org/10.1074/jbc.M114.563114.

78. Liu X, Zhang X, Ding Y, Zhou W, Tao L, Lu P, et al. Nuclear factor E2-related factor-2 negatively regulates NLRP3 Inflammasome activity by inhibiting reactive oxygen species-induced NLRP3 priming. Antioxid Redox Signal. 2017;26(1):28-43 https://doi.org/10.1089/ars.2015.6615.

79. Nasoohi S, Ismael S, Ishrat T. Thioredoxin-interacting protein (TXNIP) in Cerebrovascular and neurodegenerative diseases: regulation and implication. Mol Neurobiol. 2018;55(10):7900-20 https://doi.org/10.1007/s12 035-018-0917-z.

80. Gao P, He FF, Tang H, Lei CT, Chen S, Meng XF, et al. NADPH oxidaseinduced NALP3 inflammasome activation is driven by thioredoxininteracting protein which contributes to podocyte injury in hyperglycemia. J Diabetes Res. 2015:504761.

81. Lv H, Liu Q, Wen Z, Feng H, Deng X, Ci X. Xanthohumol ameliorates lipopolysaccharide (LPS)-induced acute lung injury via induction of AMPK GSK3ß-Nrf2 signal axis. Redox Biol. 2017;12:311-24 https://doi.org/10.1016/j. redox.2017.03.001.

82. Oslowski CM, Hara T, O'Sullivan-Murphy B, Kanekura K, Lu S, Hara M, et al. Thioredoxin-interacting protein mediates ER stress-induced $\beta$ cell death through initiation of the inflammasome. Cell Metab. 2012;16(2):265-73 https://doi.org/10.1016/j.cmet.2012.07.005.

83. Kim S, Joe Y, Jeong SO, Zheng M, Back SH, Park SW, et al. Endoplasmic reticulum stress is sufficient for the induction of IL-1 $\beta$ production via activation of the NF-kB and inflammasome pathways. Innate Immun. 2014; 20(8):799-815 https://doi.org/10.1177/1753425913508593.

84. Ishrat T, Mohamed IN, Pillai B, Soliman S, Fouda AY, Ergul A, et al. Thioredoxin-interacting protein: a novel target for neuroprotection in experimental thromboembolic stroke in mice. Mol Neurobiol. 2015;51(2): 766-78 https://doi.org/10.1007/s12035-014-8766-X.

85. Lane T, Flam B, Lockey R, Kolliputi N. TXNIP shuttling: missing link between oxidative stress and inflammasome activation. Front Physiol. 2013;4:50.

86. Hou Y, Wang Y, He Q, Li L, Xie H, Zhao Y, et al. Nrf2 inhibits NLRP3 inflammasome activation through regulating Trx1/TXNIP complex in cerebral ischemia reperfusion injury. Behav Brain Res. 2018;336:32-9 https:// doi.org/10.1016/j.bbr.2017.06.027.

87. Di Virgilio F. Liaisons dangereuses: $\mathrm{P} 2 \mathrm{X}(7)$ and the inflammasome. Trends Pharmacol Sci. 2007;28(9):465-72 https://doi.org/10.1016/j.tips.2007.07.002.

88. Di Virgilio F, Dal Ben D, Sarti AC, Giuliani AL, Falzoni S. The P2X7 Receptor in Infection and Inflammation. Immunity. 2017;47(1):15-31 https://doi.org/10.1 016/j.immuni.2017.06.020.

89. Feng L, Chen Y, Ding R, Fu Z, Yang S, Deng X, et al. P2X7R blockade prevents NLRP3 inflammasome activation and brain injury in a rat model of intracerebral hemorrhage: involvement of peroxynitrite. J Neuroinflammation. 2015;12(1):190 https://doi.org/10.1186/s12974-015-0409-2.

90. Shi F, Yang $Y$, Kouadir M, Fu Y, Yang L, Zhou $X$, et al. Inhibition of phagocytosis and lysosomal acidification suppresses neurotoxic prion peptide-induced NALP3 inflammasome activation in BV2 microglia. J Neuroimmunol. 2013;260(1-2):121-5 https://doi.org/10.1016/j.jneuroim.2 013.04.016.

91. Terada K, Yamada J, Hayashi Y, Wu Z, Uchiyama Y, Peters C, et al. Involvement of cathepsin B in the processing and secretion of interleukin1 beta in chromogranin A-stimulated microglia. Glia. 2010;58(1):114-24 https://doi.org/10.1002/glia.20906.

92. Savage CD, Lopez-Castejon G, Denes A, Brough D. NLRP3-Inflammasome Activating DAMPs Stimulate an Inflammatory Response in Glia in the Absence of Priming Which Contributes to Brain Inflammation after Injury. Front Immunol. 2012;3:288.

93. Benchoua A, Braudeau J, Reis A, Couriaud C, Onténiente B. Activation of proinflammatory caspases by cathepsin B in focal cerebral ischemia. J Cereb Blood Flow Metab. 2004;24(11):1272-9 https://doi.org/10.1097/01.WCB. 0000140272.54583.FB.
94. Kilinc M, Gürsoy-Ozdemir Y, Gürer G, Erdener SE, Erdemli E, Can A, et al. Lysosomal rupture, necroapoptotic interactions and potential crosstalk between cysteine proteases in neurons shortly after focal ischemia. Neurobiol Dis. 2010;40(1):293-302 https://doi.org/10.1016/j.nbd.2010.06.003.

95. Qin AP, Zhang HL, Qin ZH. Mechanisms of lysosomal proteases participating in cerebral ischemia-induced neuronal death. Neurosci Bull. 2008;24(2):11723 https://doi.org/10.1007/s12264-008-0117-3.

96. Sheedy FJ, Grebe A, Rayner KJ, Kalantari P, Ramkhelawon B, Carpenter SB, et al. CD36 coordinates NLRP3 inflammasome activation by facilitating intracellular nucleation of soluble ligands into particulate ligands in sterile inflammation. Nat Immunol. 2013;14(8):812-20 https://doi.org/10.1038/ni.2639.

97. Duewell P, Kono H, Rayner KJ, Sirois CM, Vladimer G, Bauernfeind FG, et al. NLRP3 inflammasomes are required for atherogenesis and activated by cholesterol crystals. Nature. 2010;464(7293):1357-61 https://doi.org/10.1038/ nature08938.

98. Rock KL, Kataoka H, Lai JJ. Uric acid as a danger signal in gout and its comorbidities. Nat Rev Rheumatol. 2013;9(1):13-23 https:/doi.org/10.1038/ nrrheum.2012.143.

99. Denoble AE, Huffman KM, Stabler TV, Kelly SJ, Hershfield MS, McDaniel GE, et al. Uric acid is a danger signal of increasing risk for osteoarthritis through inflammasome activation. Proceed Natl Acad Sci U S A. 2011;108(5):2088-93 https://doi.org/10.1073/pnas.1012743108.

100. Porter K, Lin Y, Liton PB. Cathepsin B is up-regulated and mediates extracellular matrix degradation in trabecular meshwork cells following phagocytic challenge. PLoS One. 2013;8(7):e68668 https://doi.org/10.1371/ journal.pone.0068668.

101. Akkari L, Gocheva V, Kester JC, Hunter KE, Quick ML, Sevenich L, et al. Distinct functions of macrophage-derived and cancer cell-derived cathepsin Z combine to promote tumor malignancy via interactions with the extracellular matrix. Genes Dev. 2014;28(19):2134-50 https://doi.org/10.1101/ gad.249599.114

102. Tu C, Ortega-Cava CF, Chen G, Fernandes ND, Cavallo-Medved D, Sloane BF, et al. Lysosomal cathepsin B participates in the podosome-mediated extracellular matrix degradation and invasion via secreted lysosomes in vSrc fibroblasts. Cancer Res. 2008;68(22):9147-56 https://doi.org/10.1158/ 0008-5472.CAN-07-5127.

103. Dostert C, Pétrilli V, Van Bruggen R, Steele C, Mossman BT, Tschopp J. Innate immune activation through Nalp3 inflammasome sensing of asbestos and silica. Science (New York, NY). 2008;320(5876):674-7.

104. Tang TT, Lv LL, Pan MM, Wen Y, Wang B, Li ZL, et al. Hydroxychloroquine attenuates renal ischemia/reperfusion injury by inhibiting cathepsin mediated NLRP3 inflammasome activation. Cell Death Dis. 2018;9(3):351 https://doi.org/10.1038/s41419-018-0378-3.

105. Orlowski GM, Colbert JD, Sharma S, Bogyo M, Robertson SA, Rock KL. Multiple cathepsins promote pro-IL-1 $\beta$ synthesis and NLRP3-mediated IL-1 $\beta$ activation. J Immunol. 2015;195(4):1685-97 https://doi.org/10.4049/ jimmunol.1500509.

106. Nakamura T, Furuhashi M, Li P, Cao H, Tuncman G, Sonenberg $N$, et al. Double-stranded RNA-dependent protein kinase links pathogen sensing with stress and metabolic homeostasis. Cell. 2010;140(3):338-48 https://doi. org/10.1016/j.cell.2010.01.001

107. García MA, Gil J, Ventoso I, Guerra S, Domingo E, Rivas C, et al. Impact of protein kinase PKR in cell biology: from antiviral to antiproliferative action. Microbiol Mol Biol Rev. 2006;70(4):1032-60 https://doi.org/10.1128/MMBR. 00027-06.

108. Lu B, Nakamura T, Inouye K, Li J, Tang Y, Lundbäck P, et al. Novel role of PKR in inflammasome activation and HMGB1 release. Nature. 2012; 488(7413):670-4 https://doi.org/10.1038/nature11290.

109. Yu S, Wang D, Huang L, Zhang Y, Luo R, Adah D, et al. The complement receptor C5aR2 promotes protein kinase $\mathrm{R}$ expression and contributes to NLRP3 inflammasome activation and HMGB1 release from macrophages. J Biol Chem. 2019;294(21):8384-94 https://doi.org/1 0.1074/jbc.RA118.006508.

110. Zeng Y, Qin Q, Li K, Li H, Song C, Li Y, et al. PKR suppress NLRP3-pyroptosis pathway in lipopolysaccharide-induced acute lung injury model of mice. Biochem Biophys Res Commun. 2019;519(1):8-14 https://doi.org/10.1016/j. bbrc.2019.08.054.

111. Jiang Y, Steinle JJ. Epac1 inhibits PKR to reduce NLRP3 inflammasome proteins in retinal endothelial cells. J Inflamm Res. 2019;12:153-9 https://doi. org/10.2147/JIR.S210441. 
112. Mangali S, Bhat A, Udumula MP, Dhar I, Sriram D, Dhar A. Inhibition of protein kinase $\mathrm{R}$ protects against palmitic acid-induced inflammation, oxidative stress, and apoptosis through the JNK/NF-kB/NLRP3 pathway in cultured H9C2 cardiomyocytes. J Cell Biochem. 2019;120(3):3651-63 https:// doi.org/10.1002/jcb.27643.

113. Boriushkin E, Wang JJ, Li J, Bhatta M, Zhang SX. p58(IPK) suppresses NLRP3 inflammasome activation and $I L-1 \beta$ production via inhibition of PKR in macrophages. Sci Rep. 2016;6(1):25013 https://doi.org/10.1038/srep25013.

114. Hett EC, Slater LH, Mark KG, Kawate T, Monks BG, Stutz A, et al. Chemical genetics reveals a kinase-independent role for protein kinase $\mathrm{R}$ in pyroptosis. Nat Chem Biol. 2013;9(6):398-405 https://doi.org/10.1038/ nchembio.1236.

115. He Y, Franchi L, Núñez G. The protein kinase PKR is critical for LPS-induced iNOS production but dispensable for inflammasome activation in macrophages. Eur J Immunol. 2013;43(5):1147-52 https://doi.org/10.1002/ eji.201243187.

116. Hu HJ, Song M. Disrupted lonic Homeostasis in Ischemic Stroke and New Therapeutic Targets. J Stroke Cerebrovasc Dis. 2017;26(12):2706-19 https:// doi.org/10.1016/j.jstrokecerebrovasdis.2017.09.011.

117. Edye ME, Lopez-Castejon G, Allan SM, Brough D. Acidosis drives damageassociated molecular pattern (DAMP)-induced interleukin-1 secretion via a caspase-1-independent pathway. J Biol Chem. 2013;288(42):30485-94 https://doi.org/10.1074/jbc.M113.478941.

118. Rajamäki K, Nordström T, Nurmi K, Åkerman KE, Kovanen PT, Öörni K, et al. Extracellular acidosis is a novel danger signal alerting innate immunity via the NLRP3 inflammasome. J Biol Chem. 2013;288(19):13410-9 https://doi. org/10.1074/jbc.M112.426254.

119. Deval E, Gasull X, Noël J, Salinas M, Baron A, Diochot S, et al. Acid-sensing ion channels (ASICs): pharmacology and implication in pain. Pharmacol Ther. 2010;128(3):549-58 https://doi.org/10.1016/j.pharmthera.2010.08.006.

120. Alvarez de la Rosa D, Krueger SR, Kolar A, Shao D, Fitzsimonds RM, Canessa CM. Distribution, subcellular localization and ontogeny of ASIC1 in the mammalian central nervous system. J Physiol. 2003;546(Pt 1):77-87.

121. Xiong ZG, Zhu XM, Chu XP, Minami M, Hey J, Wei WL, et al. Neuroprotection in ischemia: blocking calcium-permeable acid-sensing ion channels. Cell. 2004;118(6):687-98 https://doi.org/10.1016/j.cell.2004.08.026.

122. Gao J, Duan B, Wang DG, Deng XH, Zhang GY, Xu L, et al. Coupling between NMDA receptor and acid-sensing ion channel contributes to ischemic neuronal death. Neuron. 2005;48(4):635-46 https://doi.org/10.1016/ j.neuron.2005.10.011.

123. Krawczyk CM, Holowka T, Sun J, Blagih J, Amiel E, DeBerardinis RJ, et al. Tolllike receptor-induced changes in glycolytic metabolism regulate dendritic cell activation. Blood. 2010;115(23):4742-9 https://doi.org/10.1182/blood-2 009-10-249540.

124. Li M, Inoue K, Branigan D, Kratzer E, Hansen JC, Chen JW, et al. Acid-sensing ion channels in acidosis-induced injury of human brain neurons. J Cereb Blood Flow Metab. 2010;30(6):1247-60 https://doi.org/10.1038/jcbfm.2010.30.

125. Immke DC, McCleskey EW. Lactate enhances the acid-sensing Na+ channel on ischemia-sensing neurons. Nat Neurosci. 2001;4(9):869-70 https://doi. org/10.1038/nn0901-869.

126. Wang YZ, Wang JJ, Huang Y, Liu F, Zeng WZ, Li Y, et al. Tissue acidosis induces neuronal necroptosis via ASIC1a channel independent of its ionic conduction. eLife. 2015;4 https://doi.org/10.7554/eLife.05682.

127. Kono H, Kimura Y, Latz E. Inflammasome activation in response to dead cells and their metabolites. Curr Opin Immunol. 2014;30:91-8 https://doi. org/10.1016/j.coi.2014.09.001.

128. Fink SL, Bergsbaken T, Cookson BT. Anthrax lethal toxin and Salmonella elicit the common cell death pathway of caspase-1-dependent pyroptosis via distinct mechanisms. Proceed Natl Acad Sci U S A. 2008;105(11):4312-7 https://doi.org/10.1073/pnas.0707370105.

129. Xu YJ, Zheng L, Hu YW, Wang Q. Pyroptosis and its relationship to atherosclerosis. Clin Chim Acta. 2018;476:28-37.

130. Jia C, Chen H, Zhang J, Zhou K, Zhuge Y, Niu C, et al. Role of pyroptosis in cardiovascular diseases. Int Immunopharmacol. 2019;67:311-8 https://doi. org/10.1016/j.intimp.2018.12.028.

131. Brennan MA, Cookson BT. Salmonella induces macrophage death by caspase-1-dependent necrosis. Mol Microbiol. 2000;38(1):31-40 https://doi. org/10.1046/j.1365-2958.2000.02103.x.

132. Shi J, Gao W, Shao F. Pyroptosis: gasdermin-mediated programmed necrotic cell death. Trends Biochem Sci. 2017;42(4):245-54 https://doi.org/10.1016/j. tibs.2016.10.004
133. Dinarello CA. A clinical perspective of IL-1 $\beta$ as the gatekeeper of inflammation. Eur J Immunol. 2011;41(5):1203-17 https://doi.org/10.1002/ eji.201141550

134. Zhang D, Qian J, Zhang P, Li H, Shen H, Li X, et al. Gasdermin D serves as a key executioner of pyroptosis in experimental cerebral ischemia and reperfusion model both in vivo and in vitro. J Neurosci Res. 2019;97(6):64560 https://doi.org/10.1002/jnr.24385.

135. Abulafia DP, de Rivero Vaccari JP, Lozano JD, Lotocki G, Keane RW, Dietrich WD. Inhibition of the inflammasome complex reduces the inflammatory response after thromboembolic stroke in mice. J Cereb Blood Flow Metab. 2009;29(3):534-44 https://doi.org/10.1038/jcbfm.2008.143.

136. Li Q, Cao Y, Dang C, Han B, Han R, Ma H, et al. Inhibition of double-strand DNA-sensing CGAS ameliorates brain injury after ischemic stroke. EMBO Mol Med. 2020;12(4):e11002 https://doi.org/10.15252/emmm.201911002.

137. Li J, Hao JH, Yao D, Li R, Li XF, Yu ZY, et al. Caspase-1 inhibition prevents neuronal death by targeting the canonical inflammasome pathway of pyroptosis in a murine model of cerebral ischemia. CNS Neurosci Ther. 2020;26(9):925-39 https://doi.org/10.1111/cns.13384.

138. Mehta P, McAuley DF, Brown M, Sanchez E, Tattersall RS, Manson JJ. COVID-19: consider cytokine storm syndromes and immunosuppression. Lancet. 2020;395(10229):1033-4 https://doi.org/10.1016/S0140-6736(20)3 0628-0.

139. Qin C, Zhou L, Hu Z, Zhang S, Yang S, Tao Y, et al. Dysregulation of Immune Response in Patients With Coronavirus 2019 (COVID-19) in Wuhan, China. Clin Infect Dis. 2020;71(15):762-8 https://doi.org/10.1093/cid/ciaa248.

140. Ntaios G, Michel P, Georgiopoulos G, Guo Y, Lip GYHJS. Characteristics and Outcomes in patients with COVID-19 and acute ischemic stroke: the Global COVID-19 Stroke Registry. 2020;51(9).

141. Mao XY, Jin WL. The COVID-19 pandemic: consideration for brain infection. Neuroscience. 2020;437:130-1 https://doi.org/10.1016/j.neuroscience.2020. 04.044

142. Murta V, Villarreal A, Ramos AJ. Severe acute respiratory syndrome coronavirus 2 impact on the central nervous system: are astrocytes and microglia main players or merely bystanders? ASN Neuro. 2020;12: 1759091420954960.

143. Alam SB, Willows S, Kulka M, Sandhu JK. Severe acute respiratory syndrome coronavirus 2 may be an underappreciated pathogen of the central nervous system. Eur J Neurol. 2020;27(11):2348-60 https://doi.org/10.1111/ ene.14442.

144. Rosciszewski G, Cadena V, Auzmendi J, Cieri MB, Lukin J, Rossi AR, et al. Detrimental effects of HMGB-1 require microglial-astroglial interaction: implications for the status epilepticus-induced neuroinflammation. Front Cell Neurosci. 2019;13:380 https://doi.org/10.3389/fncel.2019.00380.

145. Murta V, Ferrari C. Peripheral inflammation and demyelinating diseases. Adv Exp Med Biol. 2016;949:263-85 https://doi.org/10.1007/978-3-319-4 0764-7_13.

146. Najjar S, Najjar A, Chong DJ, Pramanik BK, Kirsch C, Kuzniecky RI, et al. Central nervous system complications associated with SARS-CoV-2 infection: integrative concepts of pathophysiology and case reports. J Neuroinflammation. 2020;17(1):231 https://doi.org/10.1186/s12974-020-01 896-0.

147. Berger JR. COVID-19 and the nervous system. J Neurovirol. 2020;26(2):143-8 https://doi.org/10.1007/s13365-020-00840-5.

148. Song E, Zhang C, Israelow B, Lu-Culligan A, Prado AV, Skriabine S, et al. Neuroinvasion of SARS-CoV-2 in human and mouse brain. bioRxiv. 2020.

149. Scheidl E, Canseco DD, Hadji-Naumov A, Bereznai B. Guillain-Barré syndrome during SARS-CoV-2 pandemic: a case report and review of recent literature. J Perip Nervous Syst. 2020;25(2):204-7 https://doi.org/1 $0.1111 /$ jns. 12382 .

150. Schett G, Sticherling M, Neurath MFJNI. COVID-19: risk for cytokine targeting in chronic inflammatory diseases? 2020;20(5).

151. Zhou Z, Ren L, Zhang L, Zhong J, Xiao Y, Jia Z, et al. Heightened innate immune responses in the respiratory tract of COVID-19 patients. Cell Host Microbe. 2020;27(6):883-890 e2 https://doi.org/10.1016/j.chom.2020.04.017.

152. Xu Z, Shi L, Wang Y, Zhang J, Huang L, Zhang C, et al. Pathological findings of COVID-19 associated with acute respiratory distress syndrome. Lancet Respir Med. 2020;8(4):420-2 https://doi.org/10.1016/S2213-2600(20)30076-X.

153. Zhang W, Zhao Y, Zhang F, Wang Q, Li T, Liu Z, et al. The use of antiinflammatory drugs in the treatment of people with severe coronavirus disease 2019 (COVID-19): The Perspectives of clinical immunologists from China. Clin Immunol (Orlando, Fla). 2020;214:108393. 
154. Paniri A, Akhavan-Niaki H. Emerging role of IL-6 and NLRP3 inflammasome as potential therapeutic targets to combat COVID-19: role of IncRNAs in cytokine storm modulation. Life Sci. 2020;257:118114 https://doi.org/10.101 6/j.lfs.2020.118114.

155. Zhou Y, He C, Wang L, Ge B. Post-translational regulation of antiviral innate signaling. Eur J Immunol. 2017;47(9):1414-26 https://doi.org/10.1002/eji.201 746959.

156. Ribeiro DE, Oliveira-Giacomelli Á, Glaser T, Arnaud-Sampaio VF, Andrejew R, Dieckmann $L$, et al. Hyperactivation of $P 2 X 7$ receptors as a culprit of COVID19 neuropathology. Mol Psychiatry. 2020:1-16.

157. Zubair AS, Mcalpine LS, Tova G, Shelli F, Kuruvilla DE, Spudich S. Neuropathogenesis and neurologic manifestations of the coronaviruses in the Age of Coronavirus Disease 2019: a review. JAMA Neurol. 2020;77(8): $1018-27$.

158. Magro C, Mulvey JJ, Berlin D, Nuovo G, Laurence JJTR. Complement associated microvascular injury and thrombosis in the pathogenesis of severe COVID-19 infection: A report of five cases. 2020;220.

159. Hou XQ, Qin JL, Zheng XX, Wang L, Yang ST, Gao YW, et al. Potential role of high-mobility group box 1 protein in the pathogenesis of influenza H5N1 virus infection. Acta Virol. 2014;58(1):69-75.

160. Zhang Y, Xiao M, Zhang S, Xia P, Cao W, Jiang W, et al. Coagulopathy and antiphospholipid antibodies in patients with Covid-19. New Engl J Med. 2020;382(17):e38 https://doi.org/10.1056/NEJMc2007575.

161. Goshua G, Pine AB, Meizlish ML, Chang CH, Zhang H, Bahel P, et al. Endotheliopathy in COVID-19-associated coagulopathy: evidence from a single-centre, cross-sectional study. 2020;7(8).

162. Mao L, Jin H, Wang M, Hu Y, Chen S, He Q, et al. Neurologic Manifestations of hospitalized patients with coronavirus disease 2019 in Wuhan, China. JAMA Neurol. 2020;77(6):683-90 https://doi.org/10.1001/ja maneurol.2020.1127

163. Tang N, Bai H, Chen X, Gong J, Sun Z. Anticoagulant treatment is associated with decreased mortality in severe coronavirus disease 2019 patients with coagulopathy. J Thromb Haemost. 2020;18(5).

164. Markus HS, Brainin M. COVID-19 and stroke-a global World Stroke Organization perspective. Int J Stroke. 2020;15(4):361-4 https://doi.org/10.11 77/1747493020923472.

165. Gustin A, Kirchmeyer M, Koncina E, Felten P, Losciuto S, Heurtaux T, et al. NLRP3 inflammasome is expressed and functional in mouse brain microglia but not in astrocytes. PLoS One. 2015;10(6):e0130624 https://doi.org/10.13 71/journal.pone.0130624

166. Coll RC, Robertson AA, Chae JJ, Higgins SC, Muñoz-Planillo R, Inserra MC, et al. A small-molecule inhibitor of the NLRP3 inflammasome for the treatment of inflammatory diseases. Nat Med. 2015;21(3):248-55 https://doi.org/10.103 8/nm.3806.

167. Juliana C, Fernandes-Alnemri T, Wu J, Datta P, Solorzano L, Yu JW, et al. Anti-inflammatory compounds parthenolide and Bay 11-7082 are direct inhibitors of the inflammasome. J Biol Chem. 2010;285(13):9792-802 https:// doi.org/10.1074/jbc.M109.082305.

168. He Y, Varadarajan S, Muñoz-Planillo R, Burberry A, Nakamura Y, Núñez G. 3,4methylenedioxy- $\beta$-nitrostyrene inhibits NLRP3 inflammasome activation by blocking assembly of the inflammasome. J Biol Chem. 2014;289(2):1142-50 https://doi.org/10.1074/jbc.M113.515080.

169. Yan Y, Jiang W, Spinetti T, Tardivel A, Castillo R, Bourquin C, et al. Omega-3 fatty acids prevent inflammation and metabolic disorder through inhibition of NLRP3 inflammasome activation. Immunity. 2013;38(6):1154-63 https:// doi.org/10.1016/j.immuni.2013.05.015.

170. Zeng J, Chen Y, Ding R, Feng L, Fu Z, Yang S, et al. Isoliquiritigenin alleviates early brain injury after experimental intracerebral hemorrhage via suppressing ROS- and/or NF-KB-mediated NLRP3 inflammasome activation by promoting Nrf2 antioxidant pathway. J Neuroinflammation. 2017;14(1): 119 https://doi.org/10.1186/s12974-017-0895-5

171. Ai QD, Chen C, Chu S, Zhang Z, Luo Y, Guan F, et al. IMM-H004 therapy for permanent focal ischemic cerebral injury via CKLF1/CCR4-mediated NLRP3 inflammasome activation. Transl Res. 2019;212:36-53 https://doi.org/10.101 6/j.trsl.2019.05.007.

172. Wang X, Li R, Wang X, Fu Q, Ma S. Umbelliferone ameliorates cerebral ischemia-reperfusion injury via upregulating the PPAR gamma expression and suppressing TXNIP/NLRP3 inflammasome. Neurosci Lett. 2015;600:182-7 https://doi.org/10.1016/j.neulet.2015.06.016.

173. Fu C, Zhang X, Lu Y, Wang F, Xu Z, Liu S, et al. Geniposide inhibits NLRP3 inflammasome activation via autophagy in BV-2 microglial cells exposed to oxygen-glucose deprivation/reoxygenation. Int Immunopharmacol. 2020;84: 106547 https://doi.org/10.1016/j.intimp.2020.106547.

174. Qiu J, Wang M, Zhang J, Cai Q, Lu D, Li Y, et al. The neuroprotection of sinomenine against ischemic stroke in mice by suppressing NLRP3 inflammasome via AMPK signaling. Int Immunopharmacol. 2016;40:492-500 https://doi.org/10.1016/j.intimp.2016.09.024.

175. Huang MY, Tu CE, Wang SC, Hung YL, Su CC, Fang SH, et al. Corylin inhibits LPS-induced inflammatory response and attenuates the activation of NLRP3 inflammasome in microglia. BMC Complement Altern Med. 2018;18(1):221 https://doi.org/10.1186/s12906-018-2287-5.

176. Lu Y, Xiao G, Luo W. Minocycline suppresses NLRP3 inflammasome activation in experimental ischemic stroke. Neuroimmunomodulation. 2016; 23(4):230-8 https://doi.org/10.1159/000452172.

177. Zhang S, Jiang L, Che F, Lu Y, Xie Z, Wang H. Arctigenin attenuates ischemic stroke via SIRT1-dependent inhibition of NLRP3 inflammasome. Biochem Biophys Res Commun. 2017;493(1):821-6 https://doi.org/10.1016/j. bbrc.2017.08.062.

178. Zhao AP, Dong YF, Liu W, Gu J, Sun XL. Nicorandil inhibits inflammasome activation and Toll-like receptor-4 signal transduction to protect against oxygen-glucose deprivation-induced inflammation in BV-2 cells. CNS Neurosci Ther. 2014;20(2):147-53 https://doi.org/10.1111/cns.12178.

179. Yin H, Guo Q, Li X, Tang T, Li C, Wang H, et al. Curcumin suppresses IL-1 $\beta$ secretion and prevents inflammation through inhibition of the NLRP3 inflammasome. J Immunol. 2018;200(8):2835-46 https://doi.org/10.4049/ jimmunol.1701495.

180. Widiapradja A, Vegh V, Lok KZ, Manzanero S, Thundyil J, Gelderblom M, et al. Intravenous immunoglobulin protects neurons against amyloid betapeptide toxicity and ischemic stroke by attenuating multiple cell death pathways. J Neurochem. 2012;122(2):321-32 https://doi.org/10.1111/j.14 71-4159.2012.07754.x.

181. Budai MM, Varga A, Milesz S, Tőzsér J, Benkő S. Aloe vera downregulates LPS-induced inflammatory cytokine production and expression of NLRP3 inflammasome in human macrophages. Mol Immunol. 2013;56(4):471-9 https://doi.org/10.1016/j.molimm.2013.05.005.

182. Zhao J, Mou Y, Bernstock JD, Klimanis D, Wang S, Spatz M, et al. Synthetic Oligodeoxynucleotides Containing Multiple Telemeric TTAGGG Motifs Suppress Inflammasome Activity in Macrophages Subjected to Oxygen and Glucose Deprivation and Reduce Ischemic Brain Injury in Stroke-Prone Spontaneously Hypertensive Rats. PLoS One. 2015;10(10):e0140772 https:// doi.org/10.1371/journal.pone.0140772.

183. Zhang N, Zhang X, Liu X, Wang H, Xue J, Yu J, et al. Chrysophanol inhibits NALP3 inflammasome activation and ameliorates cerebral ischemia/ reperfusion in mice. Mediat Inflamm. 2014:370530.

184. Qin YY, Li M, Feng X, Wang J, Cao L, Shen XK, et al. Combined NADPH and the NOX inhibitor apocynin provides greater antiinflammatory and neuroprotective effects in a mouse model of stroke. Free Radic Biol Med. 2017;104:333-45 https://doi.org/10.1016/j. freeradbiomed.2017.01.034.

185. Inácio AR, Liu Y, Clausen BH, Svensson M, Kucharz K, Yang $Y$, et al. Endogenous IFN- $\beta$ signaling exerts anti-inflammatory actions in experimentally induced focal cerebral ischemia. J Neuroinflammation. 2015; 12(1):211 https://doi.org/10.1186/s12974-015-0427-0.

186. Zhou Y, Gu Y, Liu J. BRD4 suppression alleviates cerebral ischemia-induced brain injury by blocking glial activation via the inhibition of inflammatory response and pyroptosis. Biochem Biophys Res Commun. 2019;519(3):481-8 https://doi.org/10.1016/j.bbrc.2019.07.097.

187. Ye Y, Jin T, Zhang X, Zeng Z, Ye B, Wang J, et al. Meisoindigo protects against focal cerebral ischemia-reperfusion injury by inhibiting NLRP3 inflammasome activation and regulating microglia/macrophage polarization via TLR4/NF-KB signaling pathway. Front Cell Neurosci. 2019;13:553 https:// doi.org/10.3389/fncel.2019.00553.

188. Cao G, Jiang N, Hu Y, Zhang Y, Wang G, Yin M, et al. Ruscogenin attenuates cerebral ischemia-induced blood-brain barrier dysfunction by suppressing TXNIP/NLRP3 inflammasome activation and the MAPK pathway. Int J Mol Sci. 2016;17(9)

189. Miao H, Jiang $Y$, Geng J, Zhang B, Zhu G, Tang J. Edaravone administration confers neuroprotection after experimental intracerebral hemorrhage in rats via NLRP3 suppression. J Stroke Cerebrovasc Dis. 2020;29(1):104468 https:// doi.org/10.1016/j.jstrokecerebrovasdis.2019.104468.

190. Li X, Huang L, Liu G, Fan W, Li B, Liu R, et al. Ginkgo diterpene lactones inhibit cerebral ischemia/reperfusion induced inflammatory response in 
astrocytes via TLR4/NF-KB pathway in rats. J Ethnopharmacol. 2020;249: 112365 https://doi.org/10.1016/j.jep.2019.112365.

191. Youm YH, Nguyen KY, Grant RW, Goldberg EL, Bodogai M, Kim D, et al. The ketone metabolite $\beta$-hydroxybutyrate blocks NLRP3 inflammasomemediated inflammatory disease. Nat Med. 2015;21(3):263-9 https://doi.org/1 $0.1038 / \mathrm{nm} .3804$.

192. Jian Z, Ding S, Deng H, Wang J, Yi W, Wang L, et al. Probenecid protects against oxygen-glucose deprivation injury in primary astrocytes by regulating inflammasome activity. Brain Res. 2016;1643:123-9.

193. Li C, Wang J, Fang Y, Liu Y, Chen T, Sun H, et al. Nafamostat mesilate improves function recovery after stroke by inhibiting neuroinflammation in rats. Brain Behav Immun. 2016;56:230-45 https://doi.org/10.1016/j.bbi.2016. 03.019.

194. Thakkar R, Wang R, Sareddy G, Wang J, Thiruvaiyaru D, Vadlamudi R, et al. NLRP3 inflammasome activation in the brain after global cerebral ischemia and regulation by 17ß-estradiol. Oxidative Med Cell Longev. 2016:8309031.

195. Yang B, Sun Y, Lv C, Zhang W, Chen Y. Procyanidins exhibits neuroprotective activities against cerebral ischemia reperfusion injury by inhibiting TLR4-NLRP3 inflammasome signal pathway. Psychopharmacology. 2020;237(11):3283-93 https://doi.org/10.1007/s00213-020-05610-z.

196. Li M, Li H, Fang F, Deng X, Ma S. Astragaloside IV attenuates cognitive impairments induced by transient cerebral ischemia and reperfusion in mice via anti-inflammatory mechanisms. Neurosci Lett. 2017;639:114-9 https://doi.org/10.1016/..neulet.2016.12.046.

197. He Q, Li Z, Wang Y, Hou Y, Li L, Zhao J. Resveratrol alleviates cerebral ischemia/reperfusion injury in rats by inhibiting NLRP3 inflammasome activation through Sirt1-dependent autophagy induction. Int Immunopharmacol. 2017;50:208-15 https://doi.org/10.1016/j.intimp.2017. 06.029 .

198. Yu C, He Q, Zheng J, Li LY, Hou YH, Song FZ. Sulforaphane improves outcomes and slows cerebral ischemic/reperfusion injury via inhibition of NLRP3 inflammasome activation in rats. Int Immunopharmacol. 2017:45:748 https://doi.org/10.1016/j.intimp.2017.01.034.

199. Ren H, Kong Y, Liu Z, Zang D, Yang X, Wood K, et al. Selective NLRP3 (Pyrin Domain-Containing Protein 3) Inflammasome Inhibitor reduces brain injury after intracerebral hemorrhage. Stroke. 2018;49(1):184-92 https://doi.org/1 0.1161/STROKEAHA.117.018904.

200. Newman ZL, Sirianni N, Mawhinney C, Lee MS, Leppla SH, Moayeri M, et al. Auranofin protects against anthrax lethal toxin-induced activation of the Nlrp1b inflammasome. Antimicrob Agents Chemother. 2011;55(3):1028-35 https://doi.org/10.1128/AAC.00772-10.

201. Sheth KN, Kimberly WT, Elm JJ, Kent TA, Yoo AJ, Thomalla G, et al. Exploratory analysis of glyburide as a novel therapy for preventing brain swelling. Neurocrit Care. 2014;21(1):43-51 https://doi.org/10.1007/s12028014-9970-2.

202. Tuttolomondo A, Di Raimondo D, Pecoraro R, Maida C, Arnao V, Della Corte $\mathrm{V}$, et al. Early high-dosage atorvastatin treatment improved serum immune-inflammatory markers and functional outcome in acute ischemic strokes classified as large artery atherosclerotic stroke: a randomized trial. Medicine. 2016;95(13):e3186 https://doi.org/10.1097/ MD.0000000000003186.

203. Mo Z, Tang C, Li H, Lei J, Zhu L, Kou L, et al. Eicosapentaenoic acid prevents inflammation induced by acute cerebral infarction through inhibition of NLRP3 inflammasome activation. Life Sci. 2020;242:117133 https://doi.org/1 $0.1016 /$ /.ffs.2019.117133.

204. Guarda G, Braun M, Staehli F, Tardivel A, Mattmann C, Förster I, et al. Type I interferon inhibits interleukin-1 production and inflammasome activation. Immunity. 2011;34(2):213-23 https://doi.org/10.1016/j. immuni.2011.02.006.

205. Haneklaus M, Gerlic M, Kurowska-Stolarska M, Rainey AA, Pich D, McInnes IB, et al. Cutting edge: miR-223 and EBV miR-BART15 regulate the NLRP3 inflammasome and IL-1 $\beta$ production. J Immunol. 2012;189(8):3795-9 https:// doi.org/10.4049/jimmunol.1200312.

206. Chen S, Sun B. Negative regulation of NLRP3 inflammasome signaling. Protein Cell. 2013;4(4):251-8 https://doi.org/10.1007/s13238-013-2128-8.

207. Bauernfeind F, Rieger A, Schildberg FA, Knolle PA, Schmid-Burgk JL, Hornung $V$. NLRP3 inflammasome activity is negatively controlled by miR-223. J Immunol. 2012;189(8):4175-81 https://doi.org/10.4049/ jimmunol.1201516.

208. Yang Z, Zhong L, Xian R, Yuan B. MicroRNA-223 regulates inflammation and brain injury via feedback to NLRP3 inflammasome after intracerebral hemorrhage. Mol Immunol. 2015;65(2):267-76 https://doi.org/10.1016/j. molimm.2014.12.018.

209. Shi Y, Li K, Xu K, Liu QH. MiR-155-5p accelerates cerebral ischemiareperfusion injury via targeting DUSP14 by regulating NF-KB and MAPKs signaling pathways. Eur Rev Med Pharmacol Sci. 2020;24(3):1408-19 https:// doi.org/10.26355/eurrev_202002_20198.

210. Tian YS, Zhong D, Liu QQ, Zhao XL, Sun HX, Jin J, et al. Upregulation of miR-216a exerts neuroprotective effects against ischemic injury through negatively regulating JAK2/STAT3-involved apoptosis and inflammatory pathways. J Neurosurg. 2018;130(3):977-88 https://doi.org/10.3171/2017.5. JNS163165.

211. Chai Z, Gong J, Zheng P, Zheng J. Inhibition of miR-19a-3p decreases cerebral ischemia/reperfusion injury by targeting IGFBP3 in vivo and in vitro. Biol Res. 2020;53(1):17 https://doi.org/10.1186/s40659-020-00280-9.

212. Chen S, Smith BA, lype J, Prestipino A, Pfeifer D, Grundmann S, et al. MicroRNA-155-deficient dendritic cells cause less severe GVHD through reduced migration and defective inflammasome activation. Blood. 2015; 126(1):103-12 https://doi.org/10.1182/blood-2014-12-617258.

213. Zhang L, Liu C, Huang C, Xu X, Teng J. miR-155 knockdown protects against cerebral ischemia and reperfusion injury by targeting MafB. Biomed Res Int. 2020:6458204

214. Jiang D, Sun X, Wang S, Man H. Upregulation of miR-874-3p decreases cerebral ischemia/reperfusion injury by directly targeting BMF and BCL2L13, Biomed Pharmacother. 2019;117:108941 https://doi.org/10.1016/j.biopha.201 9.108941.

215. Bandyopadhyay S, Lane T, Venugopal R, Parthasarathy PT, Cho Y, Galam L, et al. MicroRNA-133a-1 regulates inflammasome activation through uncoupling protein-2. Biochem Biophys Res Commun. 2013:439(3):407-12 https://doi.org/10.1016/j.bbrc.2013.08.056.

216. Wang W, Ding XQ, Gu TT, Song L, Li JM, Xue QC, et al. Pterostilbene and allopurinol reduce fructose-induced podocyte oxidative stress and inflammation via microRNA-377. Free Radic Biol Med. 2015;83:214-26 https://doi.org/10.1016/j.freeradbiomed.2015.02.029.

217. Zhao Y, Zhu T, Li H, Zhao J, Li X. Transplantation of lymphocytes cocultured with human cord blood-derived multipotent stem cells attenuates inflammasome activity in ischemic stroke. Clin Interv Aging. 2019;14:226171 https://doi.org/10.2147/CIA.S223595.

218. Vahidinia Z, Azami Tameh A, Nejati M, Beyer C, Talaei SA, Etehadi Moghadam S, et al. The protective effect of bone marrow mesenchymal stem cells in a rat model of ischemic stroke via reducing the C-Jun Nterminal kinase expression. Pathol Res Pract. 2019;215(9):152519.

219. Neal EG, Acosta SA, Kaneko Y, Ji X, Borlongan CV. Regulatory T-cells within bone marrow-derived stem cells actively confer immunomodulatory and neuroprotective effects against stroke. J Cereb Blood Flow Metab. 2019; 39(9):1750-8 https://doi.org/10.1177/0271678X18766172.

220. Liu X, Hu R, Pei L, Si P, Wang C, Tian X, et al. Regulatory T cell is critical for interleukin-33-mediated neuroprotection against stroke. Exp Neurol. 2020; 328:113233 https://doi.org/10.1016/j.expneurol.2020.113233.

221. Yu Z, Wenyan T, Xuewen S, Baixiang D, Qian W, Zhaoyan W, et al. Immunological effects of the intraparenchymal administration of allogeneic and autologous adipose-derived mesenchymal stem cells after the acute phase of middle cerebral artery occlusion in rats. J Transl Med. 2018;16(1): $339 \mathrm{https} / / \mathrm{doi} .0 \mathrm{rg} / 10.1186 / \mathrm{s} 12967-018-1709-\mathrm{y}$.

222. Shiao ML, Yuan C, Crane AT, Voth JP, Juliano M, Stone LLH, et al. Immunomodulation with Human Umbilical Cord Blood Stem Cells Ameliorates Ischemic Brain Injury - A Brain Transcriptome Profiling Analysis. Cell Transplant. 2019;28(7):864-73 https://doi.org/10.1177/096368971983 6763.

223. Hocum Stone LL, Xiao F, Rotschafer J, Nan Z, Juliano M, Sanberg CD, et al. Amelioration of ischemic brain injury in rats with human umbilical cord blood stem cells: mechanisms of action. Cell Transplant. 2016;25(8):1473-88 https://doi.org/10.3727/096368916X691277.

224. Andresen L, Theodorou K, Grünewald S, Czech-Zechmeister B, Könnecke B, Lühder $F$, et al. Evaluation of the therapeutic potential of anti-TLR4-antibody MTS510 in experimental stroke and significance of different routes of application. PLoS One. 2016;11(2):e0148428 https://doi.org/10.1371/journal. pone. 0148428.

225. Ren Z, Chen L, Wang Y, Wei X, Zeng S, Zheng Y, et al. Activation of the omega-3 fatty acid receptor GPR120 protects against focal cerebral ischemic injury by preventing inflammation and apoptosis in mice. J Immunol. 2019; 202(3):747-59 https://doi.org/10.4049/jimmunol.1800637. 
226. Xie W, Zhu T, Dong X, Nan F, Meng X, Zhou P, et al. HMGB1-triggered inflammation inhibition of notoginseng leaf triterpenes against cerebra ischemia and reperfusion injury via MAPK and NF-KB signaling pathways. Biomolecules. 2019;9(10)

227. An P, Xie J, Qiu S, Liu Y, Wang J, Xiu X, et al. Hispidulin exhibits neuroprotective activities against cerebral ischemia reperfusion injury through suppressing NLRP3-mediated pyroptosis. Life Sci. 2019;232:116599 https://doi.org/10.1016/j.lfs.2019.116599.

228. Chaudhari N, Talwar P, Parimisetty A, Lefebvre d'Hellencourt C, Ravanan P. A molecular web: endoplasmic reticulum stress, inflammation, and oxidative stress. Front Cell Neurosci. 2014;8:213.

229. Benbrook DM, Long A. Integration of autophagy, proteasomal degradation, unfolded protein response and apoptosis. Exp Oncol. 2012;34(3):286-97.

230. Raturi A, Simmen T. Where the endoplasmic reticulum and the mitochondrion tie the knot: the mitochondria-associated membrane (MAM). Biochim Biophys Acta. 2013;1833(1):213-24 https://doi.org/10.1016/j.bba mcr.2012.04.013

231. Bernales S, Soto MM, Mccullagh EJFAN. Unfolded protein stress in the endoplasmic reticulum and mitochondria: a role in neurodegeneration. 2012:4(article 5):5.

232. Ding R, Ou W, Chen C, Liu Y, Li H, Zhang X, et al. Endoplasmic reticulum stress and oxidative stress contribute to neuronal pyroptosis caused by cerebral venous sinus thrombosis in rats: Involvement of TXNIP/ peroxynitrite-NLRP3 inflammasome activation. Neurochem Int. 2020;141: 104856 https://doi.org/10.1016/j.neuint.2020.104856.

233. Li Y, Li J, Li S, Li Y, Wang X, Liu B, et al. Curcumin attenuates glutamate neurotoxicity in the hippocampus by suppression of ER stress-associated TXNIP/NLRP3 inflammasome activation in a manner dependent on AMPK. Toxicol Appl Pharmacol. 2015;286(1):53-63 https://doi.org/10.1016/j.taap.201 5.03.010.

234. Guo M, Wang X, Zhao Y, Yang Q, Ding H, Dong Q, et al. Ketogenic diet improves brain ischemic tolerance and inhibits NLRP3 inflammasome activation by preventing Drp1-mediated mitochondrial fission and endoplasmic reticulum stress. Front Mol Neurosci. 2018;11:86 https://doi. org/10.3389/fnmol.2018.00086.

235. Li W, Cao T, Luo C, Cai J, Zhou X, Xiao X, et al. Crosstalk between ER stress, NLRP3 inflammasome, and inflammation. Appl Microbiol Biotechnol. 2020; 104(14):6129-40 https://doi.org/10.1007/s00253-020-10614-y.

236. Bronner DN, Abuaita BH, Chen X, Fitzgerald KA, Nuñez G, He Y, et al. Endoplasmic reticulum stress activates the inflammasome via NLRP3- and caspase-2-driven mitochondrial damage. Immunity. 2015;43(3):451-62 https://doi.org/10.1016/j.immuni.2015.08.008.

237. Burman C, Ktistakis NT. Autophagosome formation in mammalian cells. Semin Immunopathol. 2010;32(4):397-413.

238. Cecconi F, Levine B. The role of autophagy in mammalian development: cell makeover rather than cell death. Dev Cell. 2008;15(3):344-57.

239. Golstein P, Kroemer G. Cell death by necrosis: towards a molecular definition. Trends Biochem Sci. 2007;32(1):37-43.

240. Cheung EC, Ludwig RL, Vousden KH. Mitochondrial localization of TIGAR under hypoxia stimulates HK2 and lowers ROS and cell death. Proc Natl Acad Sci U S A. 2012;109(50):20491-6.

241. Vindis C. Autophagy: an emerging therapeutic target in vascular diseases. $\mathrm{Br}$ J Pharmacol. 2015;172(9):2167-78.

242. Wang Y, Meng C, Zhang J, Wu J, Zhao J. Inhibition of GSK-3 $\beta$ alleviates cerebral ischemia/reperfusion injury in rats by suppressing NLRP3 inflammasome activation through autophagy. Int Immunopharmacol. 2019; 68:234-41 https://doi.org/10.1016/j.intimp.2018.12.042.

243. Espinosa-Garcia C, Atif F, Yousuf S, Sayeed I, Neigh GN, Stein DG. Progesterone attenuates stress-induced NLRP3 inflammasome activation and enhances autophagy following ischemic brain injury. Int J Mol Sci. 2020;21(11)

244. Novel therapeutic strategies for stroke: the role of autophagy. Critical Reviews in Clinical Laboratory Sciences. 2019.

245. Wang LJ, Huang HY, Huang MP, Liou W, Chang YT, Wu CC, et al. The microtubule-associated protein EB1 links AIM2 inflammasomes with autophagy-dependent secretion. J Biol Chem. 2014;289(42):29322-33 https://doi.org/10.1074/jbc.M114.559153.

246. Xue Z, Zhang Z, Liu H, Li W, Guo X, Zhang Z, et al. lincRNA-Cox2 regulates NLRP3 inflammasome and autophagy mediated neuroinflammation. Cell Death Differ. 2019;26(1):130-45 https://doi.org/10.1038/s41418-018-0105-8.
247. Lai M, Yao H, Shah SZA, Wu W, Wang D, Zhao Y, et al. The NLRP3-Caspase 1 Inflammasome negatively regulates autophagy via TLR4-TRIF in prion peptide-infected microglia. Front Aging Neurosci. 2018;10:116 https://doi. org/10.3389/fnagi.2018.00116.

248. Shi CS, Shenderov K, Huang NN, Kabat J, Abu-Asab M, Fitzgerald KA, et al. Activation of autophagy by inflammatory signals limits IL-1 $\beta$ production by targeting ubiquitinated inflammasomes for destruction. Nat Immunol. 2012; 13(3):255-63 https://doi.org/10.1038/ni.2215.

249. Ahmed ME, lyer S, Thangavel R, Kempuraj D, Selvakumar GP, Raikwar SP, et al. Co-localization of glia maturation factor with NLRP3 inflammasome and autophagosome markers in human Alzheimer's disease brain. J Alzheimers Dis. 2017;60(3):1143-60 https://doi.org/10.3233/JAD-170634

250. Jiang P, Guo Y, Dang R, Yang M, Liao D, Li H, et al. Salvianolic acid B protects against lipopolysaccharide-induced behavioral deficits and neuroinflammatory response: involvement of autophagy and NLRP3 inflammasome. J Neuroinflammation. 2017;14(1):239 https://doi.org/10.1186/ s12974-017-1013-4.

251. Ooko E, Saeed ME, Kadioglu O, Sarvi S, Colak M, Elmasaoudi K, et al. Artemisinin derivatives induce iron-dependent cell death (ferroptosis) in tumor cells. Phytomedicine. 2015;22(11):1045-54.

252. Dixon, SJ., Lemberg, KM., et al. Ferroptosis: an iron-dependent form of nonapoptotic cell death. 2012.

253. Hassan W, Noreen H, Khalil S, Hussain A, Rehman S, Sajjad S, et al. Ethanolic extract of Nigella sativa protects Fe(II) induced lipid peroxidation in rat's brain, kidney and liver homogenates. Pak J Pharm Sci. 2016;29(1):231-7.

254. Morris G, Walker AJ, Berk M, Maes M, Puri BK. Cell death pathways: a novel therapeutic approach for neuroscientists. Mol Neurobiol. 2018;55(7):5767-86 https://doi.org/10.1007/s12035-017-0793-y.

255. Kang R, Zeng L, Zhu S, Xie Y, Liu J, Wen Q, et al. Lipid peroxidation drives gasdermin d-mediated pyroptosis in lethal polymicrobial sepsis. Cell Host Microbe. 2018;24(1):97-108.e4.

256. Liu T-I, Wang W-j, DING Y, et al. Myrrh extract alleviated ROS-mediated ferroptosis through regulating TXNIP/NLRP3 axis in ischemic stroke. 2019; 33(9):37-38

\section{Publisher's Note}

Springer Nature remains neutral with regard to jurisdictional claims in published maps and institutional affiliations.

Ready to submit your research? Choose BMC and benefit from:

- fast, convenient online submission

- thorough peer review by experienced researchers in your field

- rapid publication on acceptance

- support for research data, including large and complex data types

- gold Open Access which fosters wider collaboration and increased citations

- maximum visibility for your research: over $100 \mathrm{M}$ website views per year

At $\mathrm{BMC}$, research is always in progress.

Learn more biomedcentral.com/submissions 